\title{
Assessments of Mediterranean precipitation changes for the 21st century using statistical downscaling techniques
}

\author{
E. Hertig* and J. Jacobeit \\ Institute of Geography, University of Augsburg, Universitätsstr. 10, D-86135 Augsburg, Germany
}

\begin{abstract}
Statistical downscaling techniques are used to assess Mediterranean precipitation changes for the period 1990-2100 under increased greenhouse warming conditions from climate model output of large-scale predictor changes. Analyses are carried out on a monthly basis for the main rainy season from October to May. Results of two statistical techniques, multiple regression analysis, and canonical correlation analysis, are compared. Furthermore, differences which arise from the use of different combinations of the predictor variables, such as geopotential heights, humidity, and sea surface temperatures are discussed. Predictor output from seven different AOGCM runs (two ECHAM4/OPYC3 runs, four ECHO-G runs including a three-member ensemble, and one HadCM3 run) is used to assess Mediterranean precipitation changes in the 21 st century. Five of the AOGCM runs were forced with B2 scenario assumptions according to the special report on emission scenarios (SRES), one with SRES-A2 scenario assumptions, and one with the former IS92a scenario. Using $1000 \mathrm{hPa}-/ 500 \mathrm{hPa}$-geopotential heights and $1000 \mathrm{hPa}$-specific humidity as large-scale predictors, a shorter but wetter wet season is evident for the western and northern Mediterranean regions including precipitation increases in winter and decreases in the transitional seasons for the period 2071-2100 compared to 1990-2019. The eastern and southern parts of the Mediterranean area exhibit mainly negative precipitation changes from October to May for an increased greenhouse gas forcing.
\end{abstract}

KEY WORDS climate change; statistical downscaling; precipitation assessments; Mediterranean area

\section{Introduction}

In the context of projections of future climate change, atmosphere-ocean general circulation models (AOGCMs) are widely used to assess changes resulting from further increases of atmospheric greenhouse gases. Since the current grid size of AOGCMs ranges between 100 and $250 \mathrm{~km}$ (Houghton et al., 2001), regionalization techniques are usually applied to obtain climate change information on a regional scale. For a region like the Mediterranean area, which is characterized by complex topography and high rainfall variability, downscaling of AOGCM model output is particularly important for assessing regional climate change.

Different types of regionalization techniques have been developed recently: (1) variable resolution AGCMs (Déqué et al., 1998; Gibelin and Déqué, 2003); (2) highresolution time-slice experiments (Cubasch et al., 1996); (3) nested regional climate models (RCMs, Räisänen et al., 2004, for an overview of the nested modelling technique see Giorgi and Mearns, 1999) (4) downscaling by using synoptic analysis (Conway et al., 1996) (5) statistical downscaling approaches (von Storch et al., 1993; Gyalistras et al., 1994; Jacobeit, 1994a; Jacobeit,

\footnotetext{
* Correspondence to: E. Hertig, Institute of Geography, University of Augsburg, Universitätsstr. 10, D-86135 Augsburg, Germany. E-mail: elke.hertig@geo.uni-augsburg.de
}

1994b; Goodess and Palutikof, 1998; Murphy, 2000; Hertig, 2004). The latter are based on statistical relationships linking a set of large-scale atmospheric variables (predictors) to regional climate variables (predictands) during an observational period. The established statistical relationships have to be verified during a period independent from the calibration period, and are subsequently used to predict the future response of regional climate to climate model changes in the large-scale variables. In this study, various statistical downscaling techniques (multiple regression analysis and canonical correlation analysis, see Sections 3.1 and 4.1) will be used to assess future Mediterranean precipitation changes under increased greenhouse warming conditions. Thus, this paper gives emphasis to advanced statistical methods to obtain regional information from large-scale AOGCM output in contrast to approaches which use climate models directly to produce such fine-scale information, like (for example) the high-resolution AGCM and RCM climate change simulations for Europe (including the Mediterranean area northwards of $35^{\circ} \mathrm{N}$ ) with a horizontal grid spacing of mostly about $50 \mathrm{~km}$, conducted within the PRUDENCE project (prediction of regional scenarios and uncertainties for defining European climate change risks and effects).

The major shortcoming of the statistical downscaling approach is the basic assumption that relationships found for present climate conditions will also be valid for 
future climates under different forcings and boundary conditions (a similar restriction may be seen for the GCM parameterizations). However, this assumption may be acceptable if future mean changes do not largely exceed the present level of interannual variability. Furthermore, statistical downscaling is a computationally inexpensive technique, which can be adapted for a wide range of applications.

Several statistical studies have already dealt with anthropogenic climate change in the Mediterranean area. For instance, von Storch et al. (1993) related Iberian wintertime precipitation with North Atlantic sea level pressure fields by means of canonical correlation analysis (CCA), Corte-Real et al. (1995) used a multivariate regression approach to assess wintertime monthly precipitation at eight sites in Portugal, and Jacobeit (1994a, 1994b, 1996, 2000) linked regional precipitation in the Mediterranean area with the large-scale atmospheric circulation by multiple regression analysis. Goodess and Palutikof (1998) assessed rainfall changes for southeast Spain on a daily basis using a statistical weather generator in which rainfall occurrence is conditional on particular circulation types. Palutikof et al. (2002) statistically downscaled daily time series of temperature and rainfall for two Mediterranean catchments from HadCM2 model data. Within the framework of the statistical and regional dynamical downscaling of extremes for European regions (STARDEX) project different statistical downscaling methods are compared for the assessment of extreme events for six European regions including the Iberian Peninsula, Greece and northern Italy. A major advantage of the present study is the derivation of particular ensembles of statistical models (for details see Section 3.2), which allow us to consider non-stationarities in the circulation-climate-relationships when assessing future changes of regional climate. Furthermore, the large-scale predictors entering the statistical ensemble members for these assessments are taken not from only one selected model, but from different climate models including several numerical ensemble members with different initial conditions for one particular model. Finally, different emission scenarios used for driving the GCMs are also considered (Section 2.2).

In most studies, pressure-related predictors are used to assess regional climate variables. However, changes in rainfall cannot always be explained by circulation changes alone, atmospheric temperature and humidity may also play an important role (Wilby and Wigley, 1997; Buishand and Brandsma, 1999). Furthermore, there might be a regional sensitivity to oceanic forcing, too (Timbal et al., 1995).

In recent years, the number of potential predictors could be enlarged due to the availability of reanalysis data. These datasets include, for example, gridded values of temperature, precipitation, specific and relative humidity as well as pressure fields at different atmospheric levels, and thus, allow the incorporation of more detailed meteorological information into statistical downscaling models (Hertig, 2004; Jacobeit et al., 2007). The realism of the downscaled information thereby depends on the choice of the predictor variables and their location and spatial extent, as demonstrated by Wilby and Wigley (2000) for the example of downscaled daily precipitation at different sites in the USA from 15 different predictor variables. An important question in this context refers to the role of humidity predictors. The non-linear relationship between temperature and humidity could imply that future precipitation is more influenced by changing humidity than by rising temperatures. The selection of humidity-based predictors in statistical downscaling equations thus includes the question of what measures of moisture (absolute or relative), at which atmospheric levels, should be used to get realistic downscaling results (Sections 3.3 and 4.2). The problem of selecting appropriate atmospheric levels also applies for circulation variables. With respect to precipitation studies, arguments have been proposed to characterize the atmospheric circulation by using sea level pressure (SLP) instead of geopotential heights, because a statistical model could erroneously interpret the thermal geopotential rise due to global warming as a dynamic signal, leading to incorrect estimations of precipitation changes (Zorita et al., 2006). Therefore, a sound selection of predictor variables has to be done (Section 4.2) and an assessment of uncertainties in downscaling results has to be performed (Section 4.3) before applying appropriate models to future rainfall assessments (Section 4.4).

\section{Data}

\subsection{Observational data}

High-resolution precipitation data, uniformly covering the Mediterranean land areas, are provided by the Climatic Research Unit (CRU) (CRU05 dataset, New et al., 1999; New et al., 2000). The global dataset comprises monthly values of precipitation on a $0.5^{\circ} \times 0.5^{\circ}$ grid for terrestrial areas. Recently, there are updates of this dataset available (Oesterle et al., 2003; Mitchell et al., 2004; Mitchell and Jones, 2005) in contrast to the starting time of this study. A comparison between the different versions of this dataset revealed that there are no significant modifications for the area and time of interest justifying the use of the original dataset in this study. Furthermore, this is compatible with the particular objectives of this study, since no trend analysis is done, but rather an examination of precipitation variability in connection with the large-scale atmospheric circulation. Possible inhomogeneities in the time series at an individual grid box can therefore be neglected.

Grid boxes which show a characteristic Mediterranean precipitation regime are selected from the global dataset, resulting in 1366 grid boxes representing the Mediterranean area. The grid box selection follows that of Dünkeloh and Jacobeit (2003) in a study of Mediterranean precipitation variability in connection with largescale circulation dynamics. 
As potential large-scale atmospheric predictors for the downscaling models, the following variables have been extracted from the NCEP/NCAR reanalysis project (Kalnay et al., 1996; Kistler et al., 2001) (1) geopotential heights of various tropospheric levels for the area $20^{\circ}-70^{\circ} \mathrm{N}$ and $70^{\circ} \mathrm{W}-70^{\circ} \mathrm{E}$, as well as (2) grids of specific and relative humidity for the area $25^{\circ}-65^{\circ} \mathrm{N}$ and $30^{\circ} \mathrm{W}-45^{\circ} \mathrm{E}$ (horizontal resolution of $2.5^{\circ} \times 2.5^{\circ}$ in each case). The limits of these areas incorporate the major influences on the Mediterranean area, especially the westerlies in the upstream area. Potentially important pressure and moisture anomalies in the north and in the east of the Mediterranean area (e.g. the Russian high-pressure system) are also considered. Tests with different sizes of the domain revealed that the denoted sizes work well in terms of the subsequent dimensional reduction to meaningful principal components (PCs) and the further processing of the PCs in multiple regression analysis and CCA. Because data for the $1000 \mathrm{hPa}$ level were not available from one of the AOGCMs (HadCM3, see Section 2.2), mean sea level pressure (MSLP) and specific humidity at $2 \mathrm{~m}$ above the earth's surface have been selected from the reanalysis, too, replacing the $1000 \mathrm{hPa}$ predictors when calibrating downscaling models for future assessments with large-scale HadCM3 model output.

Sea surface temperature (SST) variability of the North Atlantic Ocean can also affect the rainfall amounts in the adjoining Mediterranean land areas (Zorita et al., 1992). Additionally, the Mediterranean Sea itself has an impact on rainfall events in the Mediterranean area, since Mediterranean cyclones are an important source for precipitation and Mediterranean cyclogenesis is distinctly influenced by air-sea interaction and latent heat release (Lionello et al., 2006b). Therefore, in addition to the atmospheric predictors, SSTs of the North Atlantic Ocean for the region $20^{\circ}-60^{\circ} \mathrm{N}\left(2^{\circ} \times 2^{\circ}\right.$ resolution $)$ from Smith et al. (1996) and of the Mediterranean Sea $\left(1^{\circ} \times 1^{\circ}\right.$ resolution) from the GISST dataset (Rayner et al., 1996) are used as potential oceanic predictors.

It should be noted that the list of predictor variables is not exhaustive at all, other predictor variables reflecting the wide range of atmospheric properties related to the processes of rainfall formation might be selected. For example, vorticity, divergence, horizontal and vertical wind components could be included. Some of them have already been used in earlier studies (Jacobeit, 1994a, b, 1996), but focussing on geopotential heights, humidity measures and SSTs considers at least important parts of the possible predictor set.

The observation-based data are used for the 1948-1998 period focussing on the main rainy season from October to May (June and September being rainy months only in parts of the Mediterranean area). Preliminary analyses with monthly up to three-monthly means revealed that the most robust results were obtained with 2-month means. For this reason, analyses are carried out for overlapping 2-month periods, i.e. October/November, November/December ... until April/May.

\subsection{Model data}

Model output from seven different AOGCM runs has been used for assessing Mediterranean precipitation changes in the 21st century (Table I for an overview of the model data employed). Two ECHAM4/OPYC3 model runs (Roeckner et al., 1996, for a description of the atmospheric part ECHAM4 and Oberhuber, 1993, for a characterization of the oceanic part OPYC3) are used based on different Intergovernmental Panel on Climate Change (IPCC) emission scenarios for the 21st century. One run was forced according to the recent SRES B2 scenario assumptions (see below) being used for the 1990-2100 period, the other model run was based on the earlier IS92a scenario ('business as usual', Houghton et al., 1992) covering the period 1948-2099. In addition, output from three ensemble members will be used, based on SRES B2 runs of the coupled model ECHO$\mathrm{G}$ with different initial conditions (Wagner, 2004). One further ECHO-G run based on SRES A2 conditions is still included allowing us to assess the range of precipitation changes according to different scenario assumptions. The climate model ECHO-G (Legutke and Voss, 1999) consists of the atmospheric model ECHAM4 and the ocean model HOPE (Wolff et al., 1997) including a dynamic-thermodynamic sea ice model from Hibler (1979).

To compare downscaling results from the output of different climate models, HadCM3 data are used in addition to the various Hamburg model runs (Gordon et al., 2000, for a description of the third version of the Hadley Centre coupled model and Pope et al., 2000, for the atmospheric part of the model). The HadCM3 model run used in this study was also forced with SRES B2 scenario conditions.

The SRES B2 scenario (Nakicenovic and Swart, 2000) is based on local and regional solutions to economic, social and environmental sustainability. It describes a world with continuously increasing global population, intermediate levels of economic development, a relatively diverse technological change and an orientation towards environmental protection. It represents a medium level of greenhouse gas emissions compared to the other SRES scenarios. By contrast, the A2 scenario describes

Table I. Overview of the seven different AOGCM runs from which predictor output has been used for assessing Mediterranean precipitation changes in the 21 st century (for details see Section 2.2).

\begin{tabular}{lcc}
\hline AOGCM & Scenario & $\begin{array}{c}\text { Time } \\
\text { period }\end{array}$ \\
\hline ECHAM4/OPYC3 & IS92a & $1948-2099$ \\
ECHAM4/OPYC3 & SRES B2 & $1990-2100$ \\
HadCM3 & SRES B2 & $1990-2100$ \\
ECHO-G (ECHAM4/HOPE) (run 1) & SRES B2 & $1990-2100$ \\
ECHO-G (ECHAM4/HOPE) (run 2) & SRES B2 & $1990-2100$ \\
ECHO-G (ECHAM4/HOPE) (run 3) & SRES B2 & $1990-2100$ \\
ECHO-G (ECHAM4/HOPE) & SRES A2 & $1990-2100$ \\
\hline
\end{tabular}


a very heterogeneous world with an emphasis on selfreliance and preservation of local identities. Economic growth and technological change are more fragmented and slower than in other storylines. The A2 scenario represents a medium-high to high level of greenhouse gas emissions.

General data preprocessing includes the fitting of the horizontal resolution of the model output data to those of the observed data (i.e. $2.5^{\circ} \times 2.5^{\circ}$ for the atmospheric variables, $2^{\circ} \times 2^{\circ}$ for North Atlantic SSTs, and $1^{\circ} \times 1^{\circ}$ for Mediterranean SSTs, respectively).

\section{Statistical downscaling}

\subsection{Statistical procedure}

As a first step, principal component analysis (PCA, e.g. Preisendorfer, 1988; von Storch and Zwiers, 1999) was separately applied to Mediterranean precipitation and the different predictor fields in order to remove linear dependencies between variables, and to reduce dimensions of the data. In the present study, S-mode (Richman, 1986), orthogonally (Varimax) rotated PCAs were carried out for different calibration periods (Section 3.2), yielding spatial centres of variation and associated time coefficients for each input field and each 2-month period. For precipitation, the spatial centres of variation are defined by groups of grid boxes with PC loadings higher than 0.5 on a particular PC. This threshold was used because it leads to non-overlapping precipitation regions covering the Mediterranean area almost entirely (Figure 1 showing the precipitation regions in January/February. (For an illustration of precipitation regions in other months see Hertig, 2004, p.154-157). The extraction of the PCs is based on the correlation matrix of the input variables. For determining the number of PCs to be extracted, the PC loadings are standardized in two different ways (1) once for each PC over all variables and (2) once for each variable over all PCs. For the extraction of a particular PC the two standardized loading values have to be greater than 1 for at least one input variable (Jacobeit, 1993), reflecting both the relevance of this PC for the input variable and its prominence in comparison to the other PCs. Depending on the analysed months, precipitation fields are reduced to 8-14 PCs with overall explained variances (EVs) between 50 and $93 \%$. Regarding geopotential height data, the 1000 and $500 \mathrm{hPa}$ levels are processed together in one combined analysis, yielding 15-18 PCs with EVs around $80 \%$. PCA condenses specific humidity fields to 15-20 PCs (EVs of 71-78\%), North Atlantic SSTs to 4-9 PCs (EVs of 82-95\%) and Mediterranean SSTs to 2-8 PCs (EVs of 90-96\%) (for detailed statistics on the ranges of the number of PCs and EVs see Hertig, 2004, p. 158-175).

Subsequently, precipitation time series of the regional centres of variation for all overlapping 2-month periods within the October-May period 1948-1998 are linked to the large-scale atmospheric and oceanic circulation represented by their corresponding PC time series. CCA (e.g. Barnett and Preisendorfer, 1987) and multiple regression analysis (e.g. Easterling, 1999; for a detailed description of both techniques see von Storch and Zwiers, 1999) are used to establish particular predictor-predictand relationships.

For each rainfall region, a stepwise regression procedure (von Storch and Zwiers, 1999, p. 166 et seqq.) is applied which combines forward selection with backward elimination. The $F$-test is used for the regression coefficients, with significance levels of $0.01-0.10$ for the intake and $0.05-0.15$ for an elimination of a variable from the regression equation, depending on which values lead to the best model quality and at the same time to the smallest number of variables possible. To test whether the inferences are made reliably, residuals are examined for normal distribution and for serial correlation using the Durbin-Watson statistic (von Storch and Zwiers, 1999, p. 157 et seq.). Further diagnostic procedures are applied to ensure that the regression models are adequate (von Storch and Zwiers, 1999, p. 150 et seqq.): tests that the input variables which enter the regression analysis are normally distributed and independent; tests for the coefficient of multiple determination and for the multiple correlation coefficient ( $F$-test with a significance level of 0.05 ), and tests for the partial regression coefficients ( $t$-test with a significance level of $0.05)$.

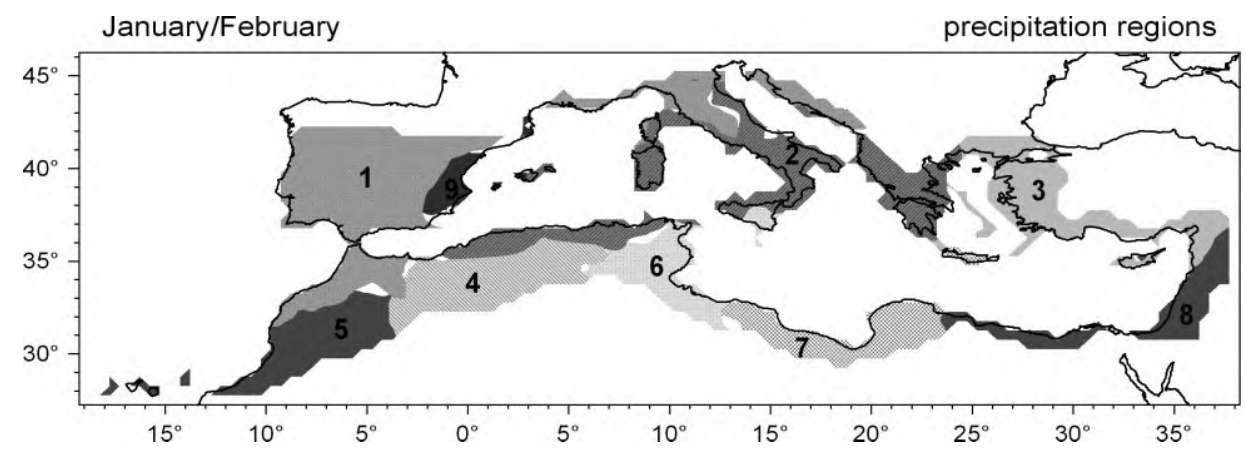

Figure 1. Precipitation regions (regions of similar precipitation variability) defined by groups of gridboxes with PC loadings higher than 0.5 on a particular PC of the s-mode, Varimax-rotated PCA of January/February-precipitation 1948-1998. The numbers in this figure correspond to the numbers of the precipitation regions (number of PC) in Table II. 
When using CCA as a statistical downscaling method (von Storch and Zwiers, 1999, p. 317 et seqq.), the number of significant canonical correlation patterns is determined by Rao's $F$-test (Rao, 1973) with a significance level of 0.05 (for illustrations of the resulting canonical correlation patterns and the associated canonical time coefficients see Hertig, 2004, p. 187-214).

The results of CCA and multiple regression analysis are used to assess the response of Mediterranean precipitation to changes of the large-scale predictors. Precipitation changes are initially calculated for the regional precipitation indices, represented by the S-mode PC time coefficients. Subsequently, a spatial back-transformation of the assessment results to the original $0.5^{\circ} \times 0.5^{\circ}$ grid is done via multiplying the index-related assessments (time coefficients) by the original PC loadings. Thus, results in Figures 3, 5, 6, 8-10 are shown after this backtransformation for the fully resolved grid fields in the Mediterranean area.

Some particular kind of cross-validation is applied in all statistical analyses to provide more reliable means for the assessment of future model performances. The requirement to verify the statistical relationships and to consider possible non-stationarities leads to a particular ensemble approach for the statistical downscaling models described in the following section.

\subsection{Calibration and verification - an ensemble approach}

The whole study period from 1948 to 1998 is divided into ten independent segments, each comprising of a different 5 -year block. The remaining 46 years in each case are used to calibrate a model, which is verified within the corresponding five independent years. Thus, for each 2-month period and for each sub-region of the Mediterranean area being analysed in particular (see below), an ensemble of ten different models is generated. The verification procedure applied to each ensemble member comprises a correlation analysis of the statistically derived precipitation data with the observation-based precipitation values from the CRU dataset. The correlation coefficient for one particular precipitation region is the 5 -year temporal mean of spatial correlation coefficients calculated for each year of the verification period between statistically derived and observed precipitation data for all grid boxes belonging to that region. Thus the number of cases entering the correlation analyses does not correspond to the small number of years in the verification periods, but to the quite larger numbers of $0.5^{\circ} \times 0.5^{\circ}$ grid boxes per region (see Table II for an example of correlation coefficients referring to the best-performing approach among different predictor combinations; for correlation coefficients in all calibration and verification periods see tables in Hertig, 2004, p. 158-173, for correlation coefficients with various predictor combinations and the two different statistical techniques see Hertig, 2004, p. 176-181). The different quality of the models in the verification periods allows us to remove the low-skill models from future assessments and to define model ensembles for the statistical assessment of future precipitation.

Cross-validation procedures are often used for short study periods (von Storch and Zwiers, 1999). Thus, Murphy (2000) assesses European temperature and precipitation on the basis of a study period of just less than 11 years, each case with 1 month taken out for validation. In the present study, some kind of cross-validation is also applied because preanalyses have shown considerable non-stationarities in the circulation-rainfall relationships. The partitioning of the study period into various segments (see above) allows a systematic elimination of those models, which exhibit no sufficiently stable connections between the large-scale circulation and Mediterranean rainfall. The appropriate models remain as ensemble members for subsequent analyses. In the present context, a model is rejected if the correlation coefficient between the statistically derived and the observed precipitation values does not exceed the threshold of 0.3 in the verification period. Since the number of cases for calculating the correlation coefficients corresponds to the number of $0.5^{\circ} \times 0.5^{\circ}$ grid boxes per region (ranging between 20 and 330), coefficients greater than 0.3 are statistically significant at least at the $10 \%$ level for every region. Although this threshold value is quite low, it has been fixed to remove just the totally inadequate models and to ensure a sufficient number of ensemble members at the same time. Furthermore, additional analyses have shown that the models of an ensemble generally represent similar circulation-rainfall relationships despite differing correlation coefficients.

Beside the issue of non-stationarity in the circulationrainfall-relationships, another difficulty for the statistical approach arises insofar as the physical drivers of future climate change are not necessarily the same as the drivers of natural interannual variations from which the downscaling models are calibrated. In order to address this problem a 'perfect model' study is performed in which one of the general circulaton model (GCM) runs is regarded as 'truth': The downscaling relationships are not calibrated from observational values but from the corresponding historical period 1948-1998 of the GCM simulation. Subsequently, future values of the predictor variables are fed in to predict future precipitation values which are compared with the future precipitation actually simulated by the GCM. The results of this analysis will be discussed in Section 4.3.

\subsection{Choice of predictors and statistical techniques}

Different predictor sets are tested to determine the bestperforming models (i.e. the models with the highest correlation coefficients between statistically estimated and observed precipitation fields in the verification periods) for the assessment of future Mediterranean precipitation (see correlation coefficients for various predictor combinations in Hertig, 2004, p. 176-181). Geopotential height anomalies have to be regarded as primary factors for the climatic variations in the Mediterranean area (von 
Table II. Correlation coefficients between statistically modelled and observation-based precipitation for each 2-month period and each Mediterranean sub-region (precipitation region) for the best-performing approach, i.e. for CCA as statistical technique and geopotential heights of the 1000 and $500 \mathrm{hPa}$ levels and specific humidity of the $1000 \mathrm{hPa}$ level as predictor variables. Values are for that statistical ensemble member with the highest correlation coefficient between statistically modelled and observation-based precipitation in the verification period.

\begin{tabular}{|c|c|c|c|c|c|c|c|c|c|c|c|c|c|c|}
\hline $\begin{array}{l}\text { Precipitation } \\
\text { region (number of PC) }\end{array}$ & 1 & 2 & 3 & 4 & 5 & 6 & 7 & 8 & 9 & 10 & 11 & 12 & 13 & 14 \\
\hline \multicolumn{15}{|l|}{ October/November } \\
\hline $\begin{array}{l}\text { Correlation coefficient } \\
\text { calibration }\end{array}$ & 0.759 & 0.625 & 0.620 & 0.648 & 0.669 & 0.709 & 0.603 & 0.629 & 0.674 & 0.676 & 0.641 & 0.783 & 0.669 & \\
\hline $\begin{array}{l}\text { Correlation coefficient } \\
\text { verification }\end{array}$ & 0.786 & 0.589 & 0.683 & 0.740 & 0.763 & 0.693 & 0.687 & 0.637 & 0.782 & 0.656 & 0.686 & 0.581 & 0.488 & \\
\hline \multicolumn{15}{|l|}{ November/December } \\
\hline $\begin{array}{l}\text { Correlation coefficient } \\
\text { calibration }\end{array}$ & 0.772 & 0.701 & 0.664 & 0.614 & 0.701 & 0.699 & 0.666 & 0.636 & 0.689 & 0.699 & 0.683 & 0.671 & 0.622 & 0.752 \\
\hline $\begin{array}{l}\text { Correlation coefficient } \\
\text { verification }\end{array}$ & 0.851 & 0.727 & 0.634 & 0.605 & 0.761 & 0.748 & 0.691 & 0.728 & 0.737 & 0.766 & 0.675 & 0.712 & 0.631 & 0.882 \\
\hline \multicolumn{15}{|l|}{ December/January } \\
\hline $\begin{array}{l}\text { Correlation coefficient } \\
\text { calibration }\end{array}$ & 0.806 & 0.750 & 0.671 & 0.617 & 0.674 & 0.678 & 0.590 & 0.655 & 0.760 & 0.624 & - & - & - & - \\
\hline $\begin{array}{l}\text { Correlation coefficient } \\
\text { verification }\end{array}$ & 0.852 & 0.847 & 0.784 & 0.562 & 0.531 & 0.752 & 0.645 & 0.559 & 0.800 & 0.546 & - & - & - & - \\
\hline \multicolumn{15}{|l|}{ January/February } \\
\hline $\begin{array}{l}\text { Correlation coefficient } \\
\text { calibration }\end{array}$ & 0.745 & 0.706 & 0.769 & 0.637 & 0.569 & 0.637 & 0.650 & 0.570 & 0.693 & - & - & - & - & - \\
\hline $\begin{array}{l}\text { Correlation coefficient } \\
\text { verification }\end{array}$ & 0.796 & 0.635 & 0.641 & 0.724 & 0.719 & 0.658 & 0.578 & 0.590 & 0.772 & - & - & - & - & - \\
\hline \multicolumn{15}{|l|}{ February/March } \\
\hline $\begin{array}{l}\text { Correlation coefficient } \\
\text { calibration }\end{array}$ & 0.788 & 0.735 & 0.698 & 0.669 & 0.664 & 0.584 & 0.637 & 0.668 & - & - & - & - & - & - \\
\hline $\begin{array}{l}\text { Correlation coefficient } \\
\text { verification }\end{array}$ & 0.799 & 0.757 & 0.767 & 0.650 & 0.710 & 0.602 & 0.552 & 0.651 & - & - & - & - & - & - \\
\hline \multicolumn{15}{|l|}{ March/April } \\
\hline $\begin{array}{l}\text { Correlation coefficient } \\
\text { calibration }\end{array}$ & 0.728 & 0.632 & 0.651 & 0.625 & 0.633 & 0.595 & 0.638 & 0.697 & 0.606 & 0.651 & 0.690 & 0.677 & - & - \\
\hline $\begin{array}{l}\text { Correlation coefficient } \\
\text { verification }\end{array}$ & 0.723 & 0.709 & 0.655 & 0.639 & 0.766 & 0.711 & 0.630 & 0.636 & 0.550 & 0.608 & 0.742 & 0.610 & - & - \\
\hline \multicolumn{15}{|l|}{ April/May } \\
\hline $\begin{array}{l}\text { Correlation coefficient } \\
\text { calibration }\end{array}$ & 0.659 & 0.706 & 0.558 & 0.591 & 0.614 & 0.612 & 0.589 & 0.602 & 0.603 & 0.650 & 0.582 & 0.691 & - & - \\
\hline $\begin{array}{l}\text { Correlation coefficient } \\
\text { verification }\end{array}$ & 0.760 & 0.768 & 0.513 & 0.786 & 0.528 & 0.566 & 0.661 & 0.715 & 0.635 & 0.642 & 0.675 & 0.603 & - & - \\
\hline
\end{tabular}

Storch, 1999; Lionello et al., 2006a). Therefore, 1000 and $500 \mathrm{hPa}$ geopotential heights are included as predictor variables for each analysis. Further levels and other potential predictors like humidity fields and SSTs are included in various combinations (Section 4.2). The different quality of the models in the verification periods is used to select the best-performing models. Thereby it is revealed that the best performance is achieved with the predictor combination $1000 \mathrm{hPa} / 500 \mathrm{hPa}$ geopotential heights, and $1000 \mathrm{hPa}$ specific humidity (the correspondent correlation coefficients are given in Table II). Generally, the improvement of model quality due to the additional inclusion of specific humidity is rather small, not exceeding a 5\% increase of shared variance between statistically modelled and observed precipitation. However, as will be discussed in Section 4.2, specific humidity can have an important impact when assessing future precipitation under different boundary conditions.

In contrast to that, SSTs of the North Atlantic Ocean and the Mediterranean Sea only sporadically exhibit a noticeable self-contained influence on Mediterranean precipitation variability. This result needs further discussion and is also taken up in Section 4.2.

Concerning the performance of the two statistical techniques used in this study (CCA and multiple regression analysis), both of them show similar results with respect to the calibration and verification periods. However, when using the verified statistical relationships to assess future precipitation from various types of predictor fields, considerable differences appear between both techniques. This will be discussed in more detail in the following section. 


\section{Results}

4.1. Comparison of results from CCA and multiple regression analysis

Differences arising from the application of different statistical techniques are shown for future predictors $(1000 \mathrm{hPa} / 500 \mathrm{hPa}$ geopotential heights and $1000 \mathrm{hPa}$ specific humidity) from the ECHAM4 run with IS92a forcing. Figure 2(a) includes smoothed time series from statistical model ensembles and corresponding cubic trends of January/February precipitation for the Iberian Peninsula, northwestern Morocco, and parts of the northern Mediterranean area (this region is indicated by filling on the inside map). The delimitation of this 'rainfall region' results from including CRU05 grid boxes with PC-loadings higher than 0.5 on that particular rainfall $\mathrm{PC}$ having its centre of variation within this region.
For the regression-based technique, there is obviously a strong dependence of the resulting precipitation time series on the particular calibration period used. The differences in total precipitation between various time series amount up to $50 \mathrm{~mm}$ for a 2-month mean value. Figure 2(b) with the January/February time series for the region around Tunisia and Sicily (defined by another rainfall PC) even indicates that the use of multiple regression analysis may lead to diverse amplitude characteristics and a different temporal evolution of the statistical ensemble members. In contrast to that, the members of the statistical ensembles resulting from CCA models show a good agreement amongst each other. Furthermore, the total range of variation and the trend progression are far more moderate when using CCA instead of multiple regression analysis.
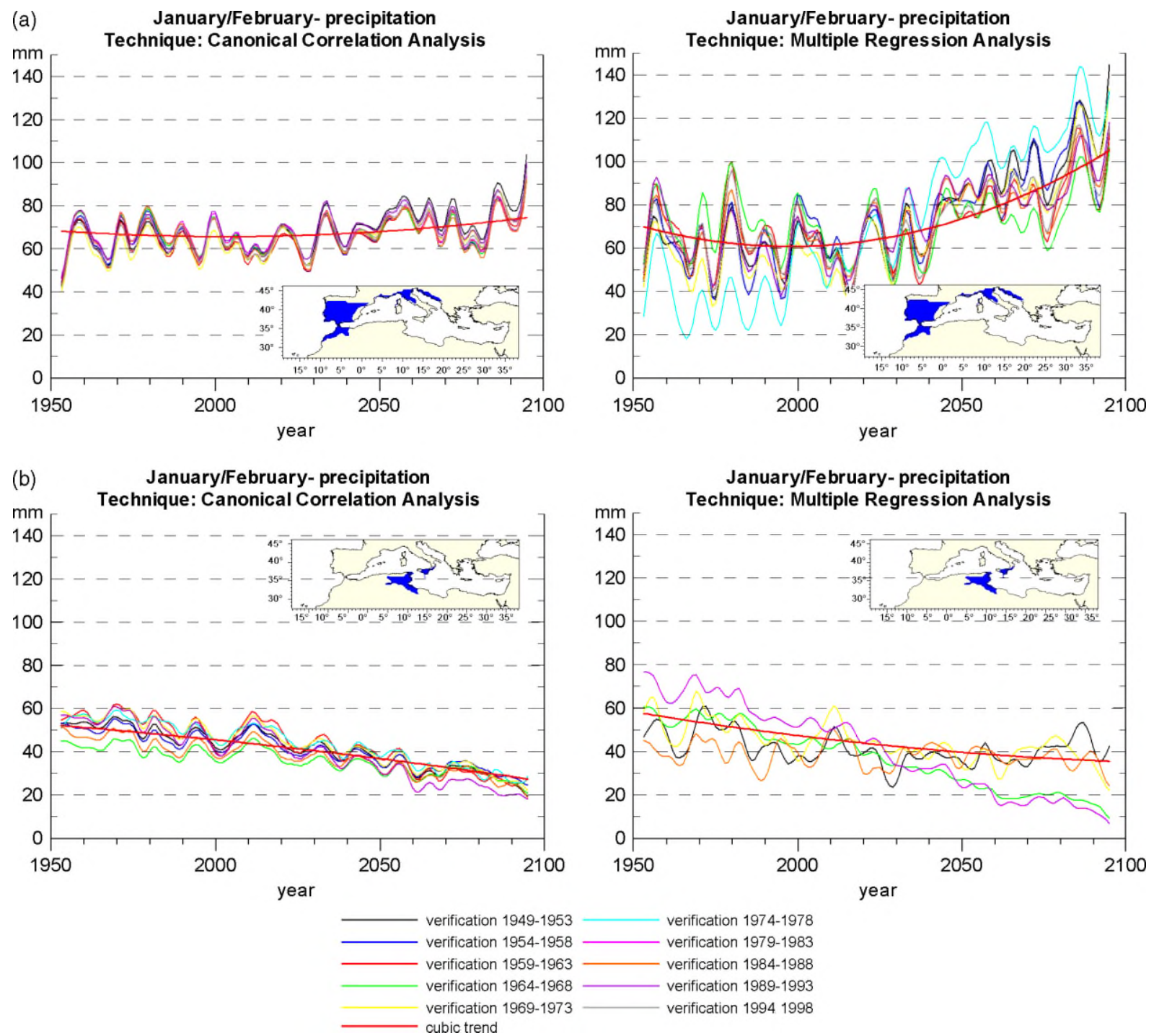

Figure 2. Smoothed time series (Gaussian low-pass filter period 11 years) and cubic trends of ten-member statistical downscaling ensembles of January/February precipitation 1948-2099 for two techniques (left side: CCA, right side: Multiple Regression Analysis) and two regions (a and b) shown by filled-out areas of the inside maps. Predictor values (1000 hPa-/500 hPa-geopotential heights and $1000 \mathrm{hPa}$-specific humidity) are from the ECHAM4/OPYC3 model run under IS92a scenario assumptions. The cubic trend is derived from that statistical model with the highest correlation between statistically modelled and observation- based precipitation. This figure is available in colour online at www.interscience.wiley.com/ijoc 
In the case of downscaling with multi-type predictors (e.g. geopotential heights, specific humidity and SSTs), CCA models show more consistency within the statistical ensembles, because relationships of regional precipitation with large-scale variables are established over the whole study areas implying some kind of 'signal smoothing'. CCA takes into account the spatial correlations of the original variables, whereas in the case of multiple regression analysis each $\mathrm{PC}$ is considered independently from the others. Unlike CCA, multiple regression analysis systematically selects those individual signals correlating best with precipitation in the calibration period. Different types of predictor variables, however, may have similar variations within this period. For instance, a certain circulation pattern implies a characteristic humidity distribution. Which one of the corresponding and synchronically varying centres of variation will finally be included in the regression model cannot be determined unambiguously by the variable selection procedure within the regression analysis, with different decisions in different calibration periods. However, under future climate conditions the synchronity of different predictor variables may not be preserved, leading to different assessment results depending on the particular predictor variables being included into a particular regression model. One way to solve this problem of multi-collinearity is a combined PCA of all predictor fields, such as done for example in a study by Xoplaki et al. (2003) for summer air temperatures in Greece. In this case, the selected empirical orthogonal functions (EOFs) reflect the combined variation of all predictors. On the other hand, performing PCA separately for each predictor type as in the present study gives instructive insights into the particular predictor-predictand relationships. This approach, however, gives more consistent results if followed by a CCA instead of a multiple regression analysis as demonstrated in this section (Figure 2).

\subsection{The influence of different predictor combinations}

First, we address the question of how many levels should be included for atmospheric predictors. In addition to the geopotential heights of the 1000 and $500 \mathrm{hPa}$ levels representing the lower and the upper tropospheric circulation, further atmospheric levels would also be conceivable for downscaling assessments. Exploratory analyses were conducted using also SLP and geopotential heights of the $200 \mathrm{hPa}$ level as large-scale circulation predictors. The highest correlation coefficients between statistically modelled and observation-based precipitation in the calibration and verification periods resulted mostly for predictors at the 1000 and $500 \mathrm{hPa}$ levels, hence the selection of geopotential height anomalies will be limited to these particular levels.

Concerning humidity, not only near-surface fields might be included, since humidity indicators of the higher troposphere might also be important predictors in the context of future climate change (Houghton et al., 2001). However, PCA of specific humidity fields at the 850 and
$500 \mathrm{hPa}$ levels reveal a very high spatial variability of these fields. Subtropical and extra-tropical tropospheric moisture is directly affected by evaporation and brought to the free atmosphere by a variety of mixing and transport processes which are governed by the complex interaction of radiation input, water and air temperatures at the surface, relative humidity, wind velocity, and the vertical temperature and water vapour pressure gradients of the extra-tropical waves (Weischet, 2002). This results in the observed small-scale structure of water vapour in the atmosphere and is also responsible for the large number of regional humidity predictors that have to be incorporated into statistical downscaling models.

An exploratory analysis with upper humidity variables as additional predictors in the statistical models did not show any improvement of model quality. Furthermore, the complex structure of tropospheric moisture distribution is not well represented in a GCM simulation with the vertical resolution currently used for climate projections. For example, Tompkins and Emanuel (2000) showed that a vertical resolution for pressure better than $25 \mathrm{hPa}$ is required. On account of this and in order to keep the number of model predictors in a reasonable range, only specific humidity at the $1000 \mathrm{hPa}$ level is used in this study.

Furthermore, relative humidity may be considered in addition to specific humidity. This has been done, for example, with respect to the probability of rainfall occurrence in Australia by Charles et al. (1999) who recommend the usage of relative moisture content (reflecting how close the atmosphere is to saturation with moisture) rather than absolute values (reflecting the total water content) to take into account the increased moisture holding capacity of the atmosphere under increased temperature conditions. Good results are obtained by Beckmann and Buishand (2002) for European stations and by Hewitson and Crane (2006) for South Africa with respect to relative humidity at the $700 \mathrm{hPa}$ level being significant for rainfall occurrence, but, on the other hand, also with respect to specific humidity of the $700 \mathrm{hPa}$ level being significant for rainfall amounts. In contrast to the results of Beckmann and Buishand (2002), specific and relative humidity was rarely selected in a study by Murphy (2000) who fitted linear regression equations to monthly rainfall amounts in Europe. In the present study, tests with models including relative humidity of the $1000 \mathrm{hPa}$ level as additional predictor did not show any enhancement of model quality either. Therefore, only specific humidity is used as moisture-predictor to assess changes of total precipitation amounts.

For further comparisons of different predictor combinations, large-scale variables were taken from the ECHAM4/OPYC3 run with SRES B2 scenario conditions for the period 1990-2100. Downscaling results for different predictor combinations are presented in Figure 3 comparing statistically modelled January/February precipitation for the two 30-year periods 2071-2100 and 1990-2019 (as differences in absolute amounts as well as in terms of changing percentages for the fully 
(a) $1000 \mathrm{hPa}-/ 500 \mathrm{hPa}-$ geopotential heights
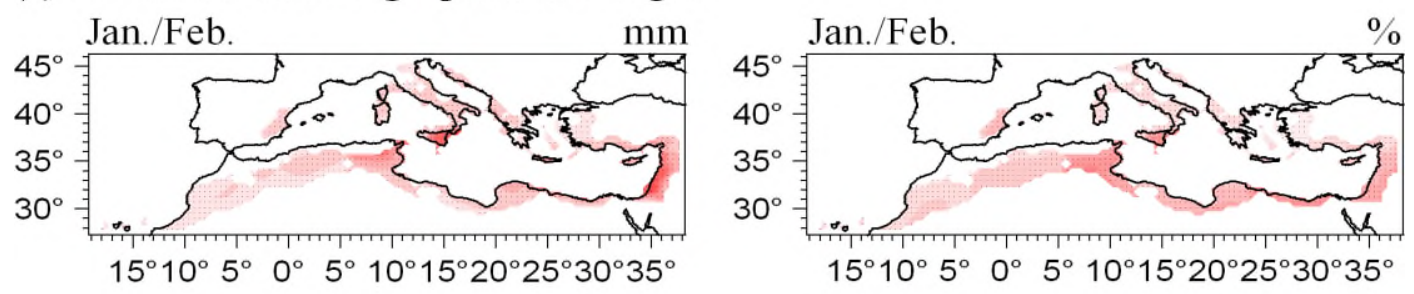

(b) 1000hPa-/500hPa- geopotential heights and 1000hPa- specific humidity
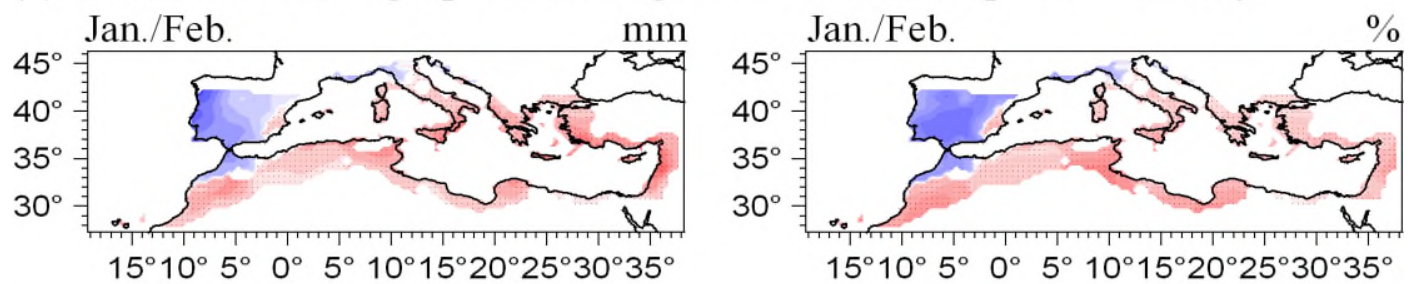

(c) $1000 \mathrm{hPa}-/ 500 \mathrm{hPa}-$ geopotential heights and North Atlantic SST
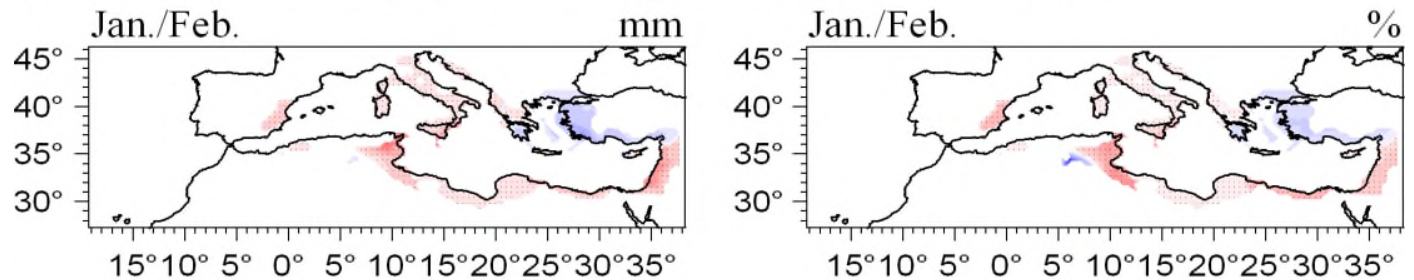

(d) $1000 \mathrm{hPa}-/ 500 \mathrm{hPa}-$ geopotential heights and Mediterranean SST
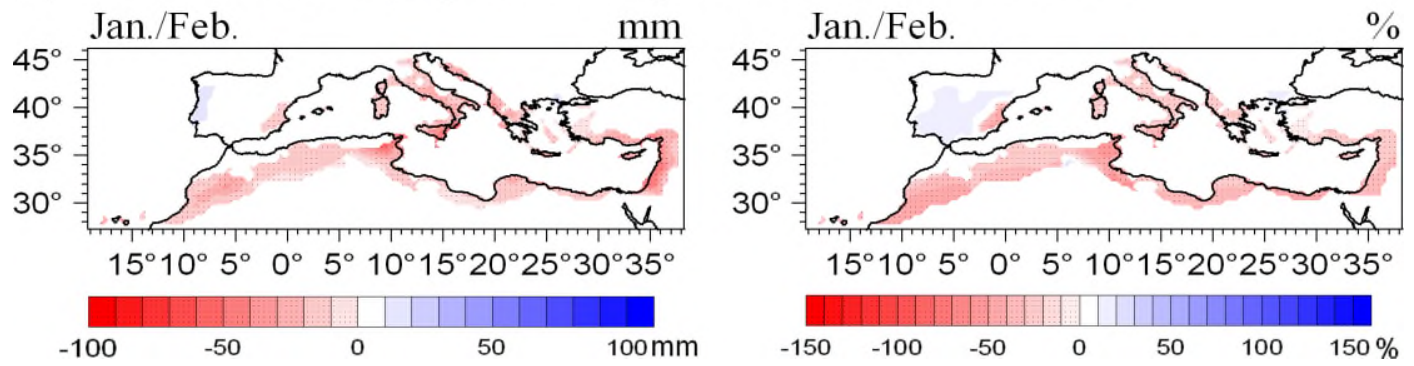

Figure 3. Change of the mean January/February- precipitation between the periods 2071-2100 and 1990-2019: differences in mm (left side) and percentages in relation to the 1990-2019 mean (right side). Climate model: ECHAM4/OPYC3, scenario: SRESB2, statistical downscaling technique: CCA. Figure 3(a): Predictors: $1000 \mathrm{hPa} / 500 \mathrm{hPa}$-geopotential heights. Figure 3(b): Predictors: $1000 \mathrm{hPa} / 500 \mathrm{hPa}-\mathrm{geopotential}$ heights and $1000 \mathrm{hPa}$-specific humidity. Figure 3(c): Predictors: $1000 \mathrm{hPa}-/ 500 \mathrm{hPa}$-geopotential heights and SSTs of the North Atlantic, Figure 3(d): Predictors: $1000 \mathrm{hPa} / 500 \mathrm{hPa}$-geopotential heights and Mediterranean SSTs. This figure is available in colour online at www.interscience.wiley.com/ijoc

resolved $0.5^{\circ} \times 0.5^{\circ}$ grid fields). Figure $3(\mathrm{a})$ is based on $1000 \mathrm{hPa} / 500 \mathrm{hPa}$ geopotential heights as the only predictors, Figure 3(b) includes, additionally, the $1000 \mathrm{hPa}$ specific humidity fields. Figure 3(c) combines the geopotential heights with North Atlantic SSTs, and Figure 3(d) with Mediterranean SSTs.

For the eastern and southern Mediterranean regions, almost no distinctions appear, all predictor combinations lead to reduced rainfall amounts at the end of the 21 st century. In contrast to that, no consistent precipitation changes can be seen for the Iberian Peninsula and areas around the Aegean Sea. The prominent differences occurring for the Iberian Peninsula are singled out for further discussions with respect to Figure 4 showing the time series ensembles of January/February precipitation resulting from different predictor combinations. The location of the Iberian Peninsula on the southern side of the extra-tropical westerlies implies that geopotential heights and specific humidity anomalies as well as North Atlantic SSTs should be decisive predictors in the upstream area of the reference region. Thus, results are shown for $1000 \mathrm{hPa} / 500 \mathrm{hPa}$ geopotential heights as the only large-scale predictors, and for further combinations with either $1000 \mathrm{hPa}$ specific humidity fields or North Atlantic SSTs. The additional inclusion of specific humidity into the predictor fields alters the precipitation time series ensemble in such a way that there is a stronger upward trend in precipitation during the 21 st century (Figure 4(b)) compared to the assessment using only geopotential heights as large-scale 
(a) January/February-precipitation Predictors: $1000 \mathrm{hPa}-1500 \mathrm{hPa}$-geopotential heights

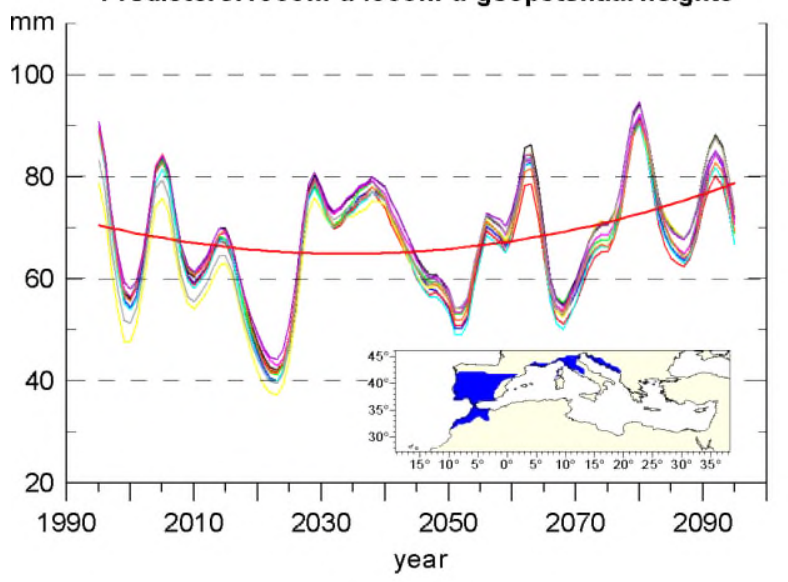

\section{(c) January/February-precipitation Predictors: $1000 \mathrm{hPa}-1500 \mathrm{hPa}$-geopotential heights, North Atlantic SST}

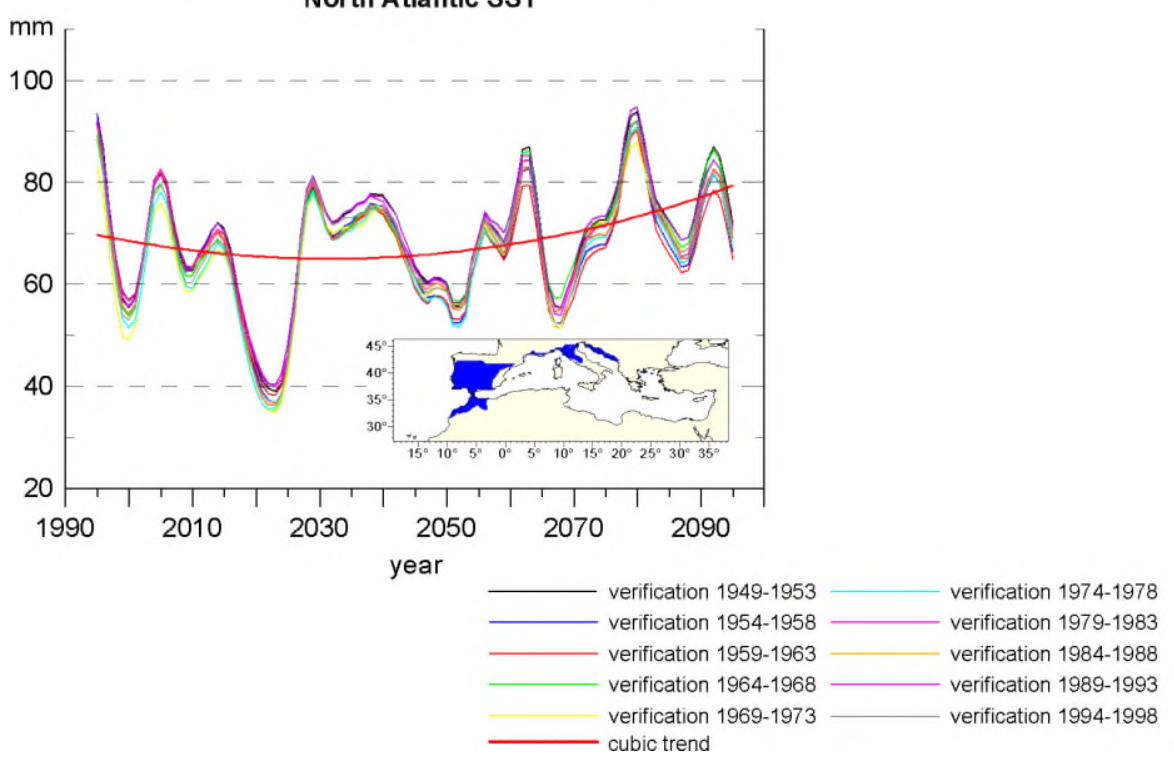

(b) January/February-precipitation

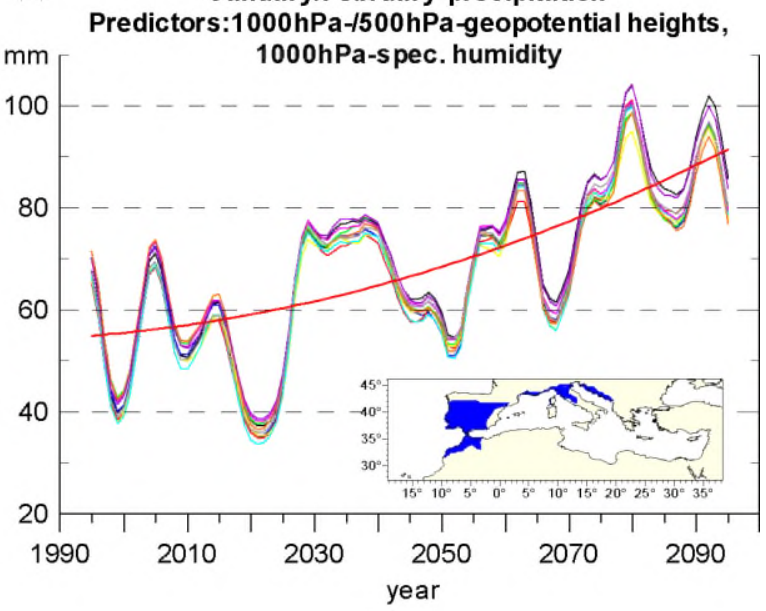

Figure 4. Smoothed time series (Gaussian low-pass filter period 11 years) and cubic trends of ten-member statistical downscaling ensembles of January/February precipitation 1990-2100 for three different predictor combinations ((a): $1000 \mathrm{hPa}-/ 500 \mathrm{hPa}$-geopotential heights, (b): $1000 \mathrm{hPa}-1500 \mathrm{hPa}$-geopotential heights and $1000 \mathrm{hPa}$-specific humidity, (c): $1000 \mathrm{hPa}-/ 500 \mathrm{hPa}$-geopotential heights and SSTs of the North Atlantic) for a region shown by filled-out area of the inside maps. Predictor values are from the ECHAM4/OPYC3 model run under SRESB2 scenario assumptions. The statistical downscaling technique is CCA. The cubic trend is derived from that statistical model with the highest correlation between statistically modelled and observation-based precipitation. This figure is available in colour online at www.interscience.wiley.com/ijoc

predictors (Figure 4(a)). This is consistent with the fact that increasing temperatures due to enhanced greenhouse gas forcing tend to increase the evaporation term of the surface energy budget, owing to the increase in water vapour capacity of the boundary layer. Since moisture convergence is likely to be proportionally enhanced as the moisture content increases, it should lead to similarly enhanced precipitation rates (Houghton et al., 2001).

Furthermore, it is worth mentioning that the inclusion of specific humidity within the predictor fields causes only small changes in model quality during the observation periods, but can gain particular importance in describing future climate change. Taking as an example the spatial structures and the mean change of specific humidity of January/February, between the beginning and the end of the scenario period, the whole Mediterranean area is affected by moisture increases in the range of $1-1.5 \mathrm{~g} / \mathrm{kg}$ (for trends in the other months and in the other predictor fields see Hertig, 2004, p. 217-220). In the current climate period, the lowest values of January/February specific humidity within the study domain occur over the Alps and the central mountains of Spain, whereas at the end of the scenario period the minimum is located over the east of the Baltic Sea. In contrast to that, there is neither an improvement in statistical model quality for the calibration and verification periods nor a notable modification of future precipitation when North Atlantic SSTs are included as additional predictors 
(Figure 4(c)). There are different possible reasons for this lack in additional predictive skill of SSTs for Mediterranean precipitation: for example, the influence of SSTs on Mediterranean precipitation may operate on different time scales (e.g. on an interdecadal time scale, Bigg et al., 2003), or the relationships are generally of a non-linear nature (Palmer, 1999). It is also possible that the relevant ocean variability is already included within the
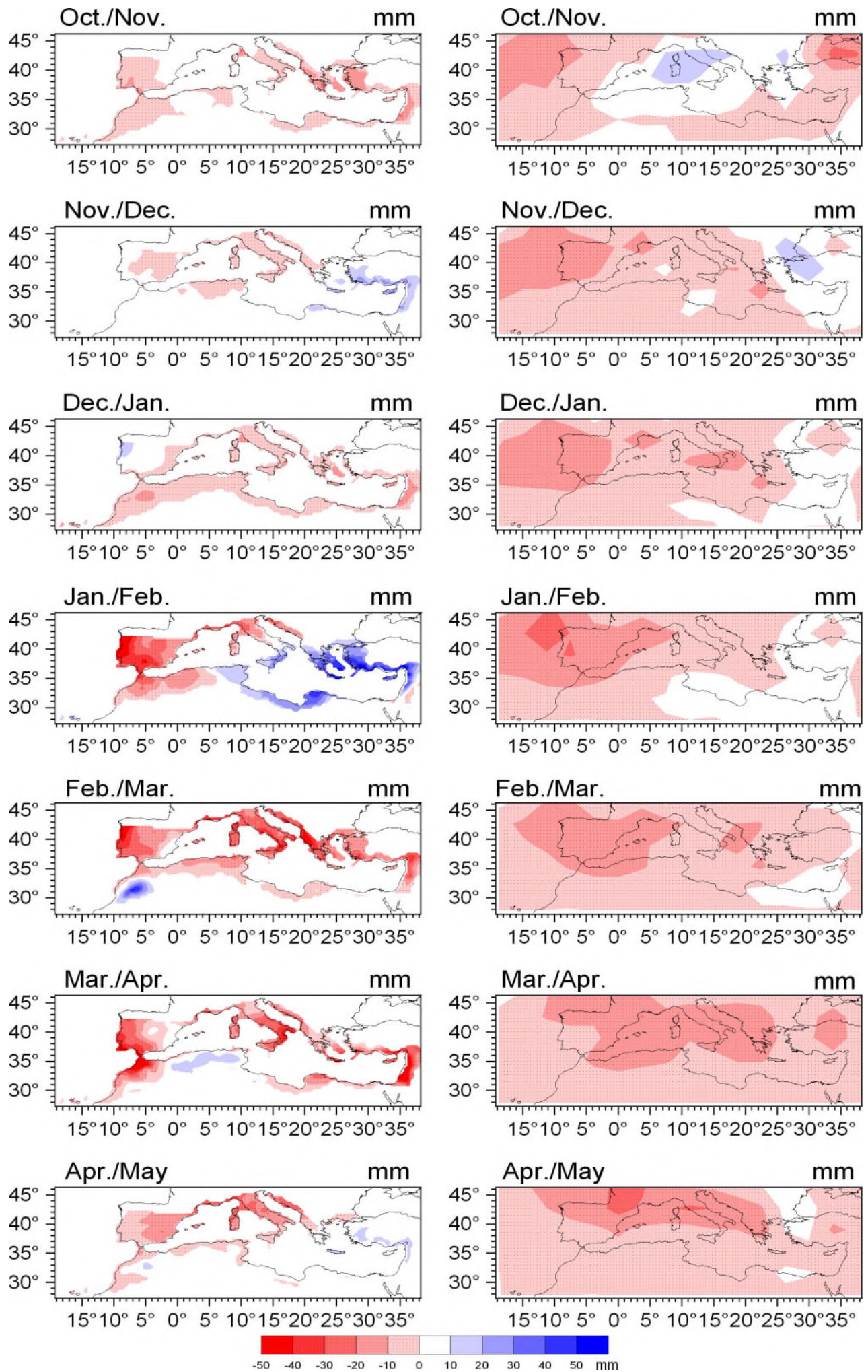

Figure 5. Differences of the mean 2-month precipitation between the periods 2071-2100 and 1990-2019 in mm. Left side: statistical downscaling results based on CCA and using ECHO-G (1) predictors (1000 hPa-/500 hPa-geopotential heights and $1000 \mathrm{hPa}$-specific humidity). Note that values are available only for the terrestrial areas. Right side: Precipitation differences calculated from the direct precipitation output of the ECHO-G (1) run. Scenario: SRES B2. This figure is available in colour online at www.interscience.wiley.com/ijoc 
atmospheric variables, such as the strong relationship of the North Atlantic Oscillation (NAO) with underlying SSTs (Wanner et al., 1997). Thus, the inclusion of SST predictors into the statistical models would not provide a new source of information, it would only mean a pointless increase in the number of selected predictors. Since an SST-precipitation-coupling cannot be isolated in statistical terms - being also evident from low correlation coefficients in the verification periods, when using SSTs as the only predictor - even the substantially increased SSTs under increased greenhouse warming conditions will not be able to impact on the evolution of Mediterranean precipitation in the 21st century (Figure 4).

Summing up the results of this section, the best performance of statistical downscaling models is achieved with the predictor combination $1000 \mathrm{hPa} / 500 \mathrm{hPa}$ geopotential heights and $1000 \mathrm{hPa}$ specific humidity which will be used further for uncertainty studies (Section 4.3) and for future rainfall assessments (Section 4.4).

\subsection{Uncertainty of the downscaling results}

In order to assess whether the downscaling relationships capture the response to greenhouse gas forcing correctly, a 'perfect model' study is performed. One of the GCM runs is regarded as 'truth', in this case the ECHO-G ensemble member 1 . The downscaling relationships are calibrated from the historical values (years 1948-1998) of the GCM predictors $1000 \mathrm{hPa}-/ 500 \mathrm{hPa}$-geopotential heights and $1000 \mathrm{hPa}$-specific humidity using CCA as the statistical technique. Subsequently, the future values of these model predictors are used for a statistical assessment of Mediterranean precipitation in the 21 st century. The left side of Figure 5 shows the results for each 2-month analysis in terms of twomonthly mean differences between the 30-year periods 2071-2100 and 1990-2019. Additionally, the right side of Figure 5 shows the corresponding precipitation differences for the same 30-year periods as actually simulated by the large-scale ECHO-G model (ensemble member 1).

According to Figure 5 the patterns of climate change simulated in the ECHO-G run are largely preserved during the statistical downscaling procedure for the autumn and spring months. But during the winter months some differences appear, for example, the statistically downscaled precipitation decreases in some southern parts of the Mediterranean area during December/January, and the stronger increases over a wide area of the eastern Mediterranean in January/February which cannot be found in the direct GCM output. To enable a quantitative comparison between the two results, the ECHO-G precipitation is rescaled by an ordinary kriging routine to the same spatial resolution as for the downscaled precipitation. Afterwards, confidence intervals are calculated for the ECHO-G rainfall (for details of their calculation see at the end of this section) to see whether the downscaling results fall within the range of model variability. For the autumn and spring months, downscaling results lie within the $99 \%$ confidence intervals of the model precipitation. For the winter months, differences between downscaling results and the direct ECHO-G output appear for some regions of northern Africa, the Levant, and the southern parts of Greece, hence areas which exhibit a large natural interannual variability (not shown).

This leads to the conclusion that not all physical drivers of future climate change might be properly captured in the downscaling equations. Reasons for that are associated (1) with the 50-year training period which is too short to capture all interannual variations particularly over north Africa (2) with the predictors-rainfall relationships from this training period which might be somewhat modified under enhanced greenhouse warming conditions (Sections 4.1 and 4.2) and (3) with the non-incorporation of other important predictor types into the statistical downscaling equations.

Yet the statistically downscaled precipitation bears a substantial resemblance to the direct precipitation output, implying that the relationships between the largescale predictors and Mediterranean rainfall are properly established in the calibration period and that these relationships generally hold under increased greenhouse gas forcing. Considering that the GCM geopotential height values have a higher reliability than the GCM precipitation values (e.g. Covey et al., 2000; Min et al., 2005), the skill of the statistical downscaling becomes obvious. The robust and comprehensible results obtained from the statistical downscaling of precipitation from geopotential heights data stand as a very important source of information next to the rather uncertain GCM precipitation output.

Beyond those uncertainties that are related to the statistical approach, further uncertainties arise from the future emission scenarios and from the particular GCM response to a given forcing scenario. The latter is mainly considered by ensemble approaches. A comparison of direct precipitation output from the three ECHO-G ensemble members used in this study shows some differences in the autumn and winter months (for example in the ECHO-G run 2 there are precipitation increases for the northwestern Mediterranean area in January/February which are not reproduced in the other ECHO-G runs), whereas all GCM runs yield rainfall decreases for the whole Mediterranean area in spring (not shown). Another source of uncertainty inherent to the GCMs is related to missing or misrepresented physical processes (being reduced by continual model improvements).

Some sources of uncertainty are also taken into account by the present downscaling approach considering predictor output from different GCMs and from different ensemble member runs (Section 4.4). Of course, this sample of different GCM runs is still too small to capture the entire uncertainty arising from variations in GCM physics or initial conditions, but it illustrates to some degree these substantial uncertainties.

Finally, the downscaling assessments, as described in the next section, include the calculation of confidence intervals for the rainfall differences between the 30-year 


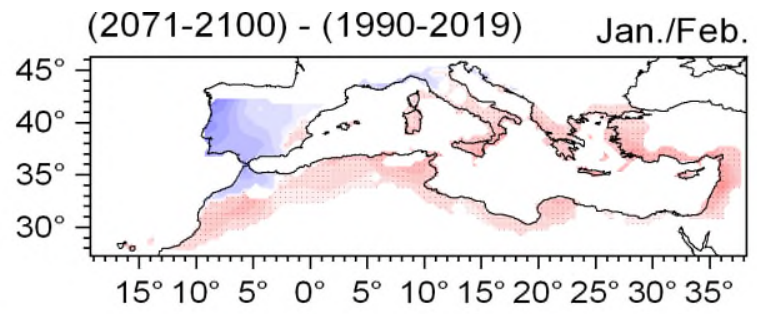

lower limit of 95\%-confidence interval

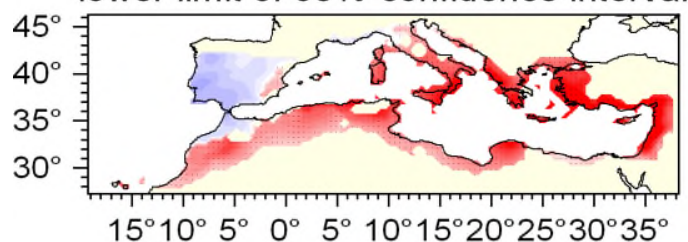

upper limit of $95 \%$ confidence interval
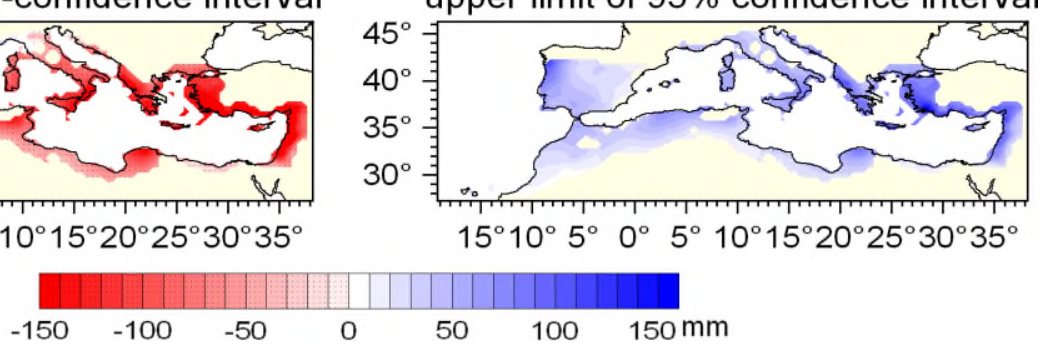

Figure 6. Difference of the mean January/February- precipitation between the periods 2071-2100 and 1990-2019 and corresponding lower and upper limits of the $95 \%$ confidence interval. Assessment based on ECHAM4/OPYC3- model predictor values of $1000 \mathrm{hPa} / 500 \mathrm{hPa}$-geopotential heights and $1000 \mathrm{hPa}$-specific humidity. Scenario: SRESB2. Downscaling technique: CCA. This figure is available in colour online at www.interscience.wiley.com/ijoc

periods 2071-2100 and 1990-2019. The standard deviations required for the calculation of these intervals are derived - separately for each 2-month period and each sub-region - from the sample of the individual rainfall differences between 2071 and 1990, 2072 and 1991,..., 2100 and 2019. Within these 95\% confidence intervals, both increases and decreases of rainfall may occur for almost every region and every 2-month period considered. The only exceptions are rainfall increases at the east coast of Spain in October/November, in the western Mediterranean area and northern Italy from December to February, and in parts of the Atlas Mountains in February/March. Only in these cases is the sign of the estimated rainfall increase maintained throughout the whole confidence interval. As an example, Figure 6 shows the estimated January/February rainfall changes (derived from predictor values of the ECHAM4 scenario B2 run) and the corresponding lower and upper limits of the $95 \%$ confidence intervals. The western Mediterranean rainfall increases are preserved within this given range, whereas stronger decreases and even slight increases are possible for the other Mediterranean regions. Again, the assessments of future rainfall changes are restricted by a high degree of uncertainty, a common problem of such kinds of scenarios as already pointed out above and e.g. by Palutikof and Wigley (1996).

\subsection{Mediterranean precipitation in the 21st century} under increased greenhouse warming conditions

Results in this section are mainly based on assessments of Mediterranean precipitation changes under SRES B2 scenario assumptions, using CCA as the statistical downscaling technique and the best-performing predictorcombination $(1000 \mathrm{hPa} / 500 \mathrm{hPa}$ geopotential heights and $1000 \mathrm{hPa}$ specific humidity) from an ensemble of various ECHAM4 model runs. Output from another model
(HadCM3) was also used, in this case with MSLP, $500 \mathrm{hPa}$ geopotential heights and $2 \mathrm{~m}$ specific humidity as large-scale predictors. Downscaling results using an ECHAM4 model run with SRES A2 forcing are outlined as well. For each 2-month analysis the differences of statistically modelled mean precipitation amounts for the 30-year periods $2071-2100$ and 1990-2019 as well as the corresponding percentage changes are shown in Figure 8, based on data from the statistical model with the highest correlation between statistically modelled and observed precipitation. For ranges between the statistical downscaling results arising from the use of predictor output of different GCM ensemble members and of predictor output from a different climate model see Figures 9 and 10 (for an example of direct GCM precipitation output, go back to the right side of Figure 5). Results are presented with the full spatial resolution of the $0.5^{\circ} \times 0.5^{\circ}$ grid after back-transformation from the regional rainfall indices (already described in Section 3.1).

In addition, significance of the statistically downscaled changes in Mediterranean precipitation is evaluated in terms of the 'signal-to-noise-ratio' ( $\mathrm{S} / \mathrm{N}$ ) (see for example Rapp and Schönwiese, 1995). The estimated precipitation time series meet the requirement of normal distribution according to the Kolmogorov-Smirnov goodness-of-fit test (95\% level of significance). The $\mathrm{S} / \mathrm{N}$ is obtained by setting the rainfall difference of the two 30-year periods in relation to natural variability, represented by the standard deviation of interannual variations within the earlier period. As a result, regions with $\mathrm{S} / \mathrm{N}>1$ (transverse hatching in Figure 8(b)) depict areas with signals greater than the mean recent natural variability, those with $\mathrm{S} / \mathrm{N}>1.96$ (cross hatching in Figure 8(b)) areas with changes being significant at the $95 \%$ level.

Summarizing the various downscaling results we may conclude that all different assessments show similar 

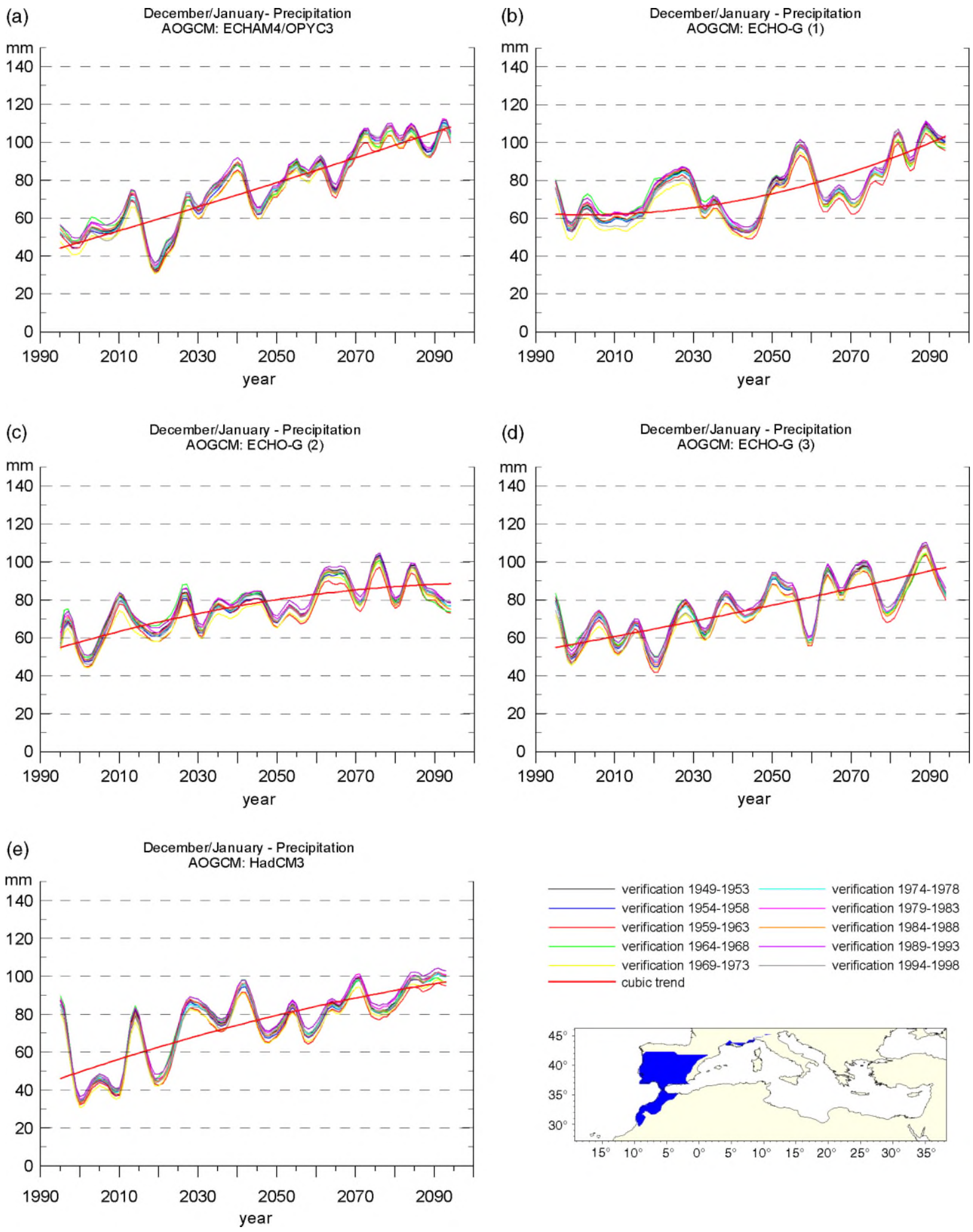

Figure 7. Smoothed time series (Gaussian low-pass filter period 11 years) and cubic trends of ten-member statistical downscaling ensembles of January/February precipitation 1990-2100 for five different model runs ((a): ECHAM4/OPYC3 run, (b)-(d): ECHO-G runs, (e): HadCM3 run) under SRESB2 scenario assumptions for a region shown by filled-out area of the bottom right map. The downscaling technique is CCA. The cubic trend is derived from that statistical model with the highest correlation between statistically modelled and observation-based precipitation. This figure is available in colour online at www.interscience.wiley.com/ijoc

tendencies of future precipitation changes in the Mediterranean area. While the general development is in agreement, individual monthly precipitation values, shortand medium-term variations, and the particular trend characteristics differ from one assessment to the other. This may be seen from Figure 7 showing the smoothed time series and cubic trends of December/January precipitation for the region around the Iberian Pensinsula 
(a) Oct./Nov.

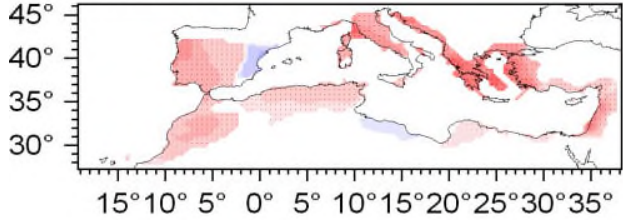

Nov./Dec.

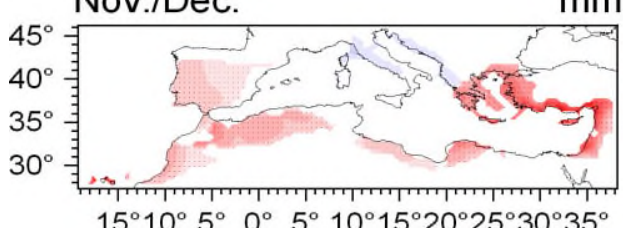

Dec./Jan.

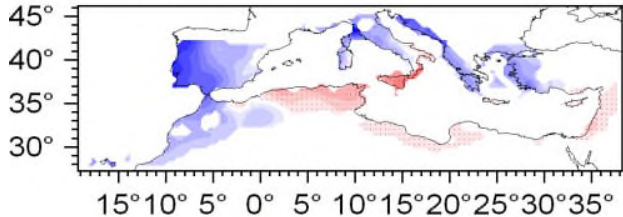

$15^{\circ} 10^{\circ} 5^{\circ} 0^{\circ} 5^{\circ} 10^{\circ} 15^{\circ} 20^{\circ} 25^{\circ} 30^{\circ} 35^{\circ}$

Jan./Feb.

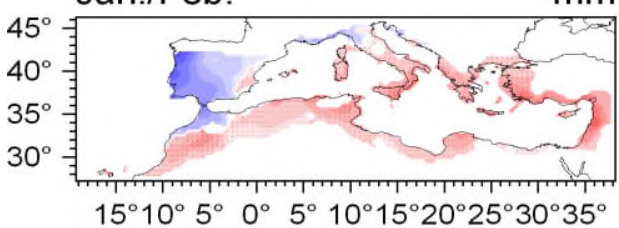

Feb./Mar.

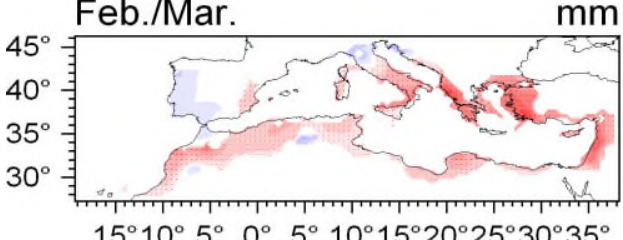

$15^{\circ} 10^{\circ} 5^{\circ} 0^{\circ} 5^{\circ} 10^{\circ} 15^{\circ} 20^{\circ} 25^{\circ} 30^{\circ} 35^{\circ}$

Mar./Apr.

$\mathrm{mm}$
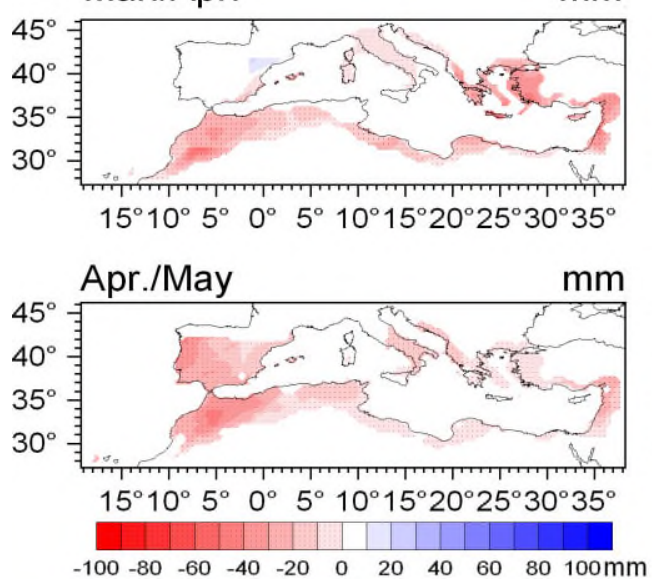

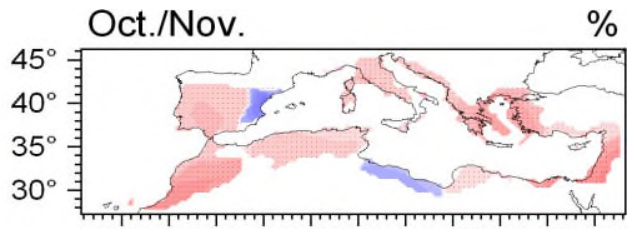

$15^{\circ} 10^{\circ} 5^{\circ} 0^{\circ} 5^{\circ} 10^{\circ} 15^{\circ} 20^{\circ} 25^{\circ} 30^{\circ} 35^{\circ}$

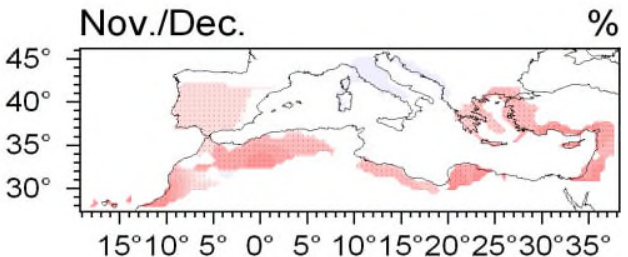

Dec./Jan.

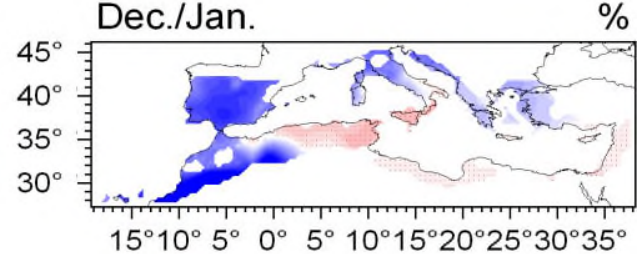

Jan./Feb

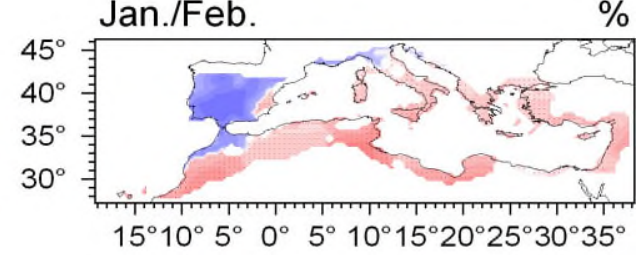

Feb./Mar.

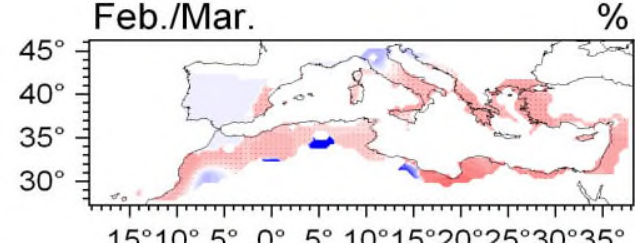

$15^{\circ} 10^{\circ} 5^{\circ} 0^{\circ} 5^{\circ} 10^{\circ} 15^{\circ} 20^{\circ} 25^{\circ} 30^{\circ} 35^{\circ}$

Mar./Apr. $\%$
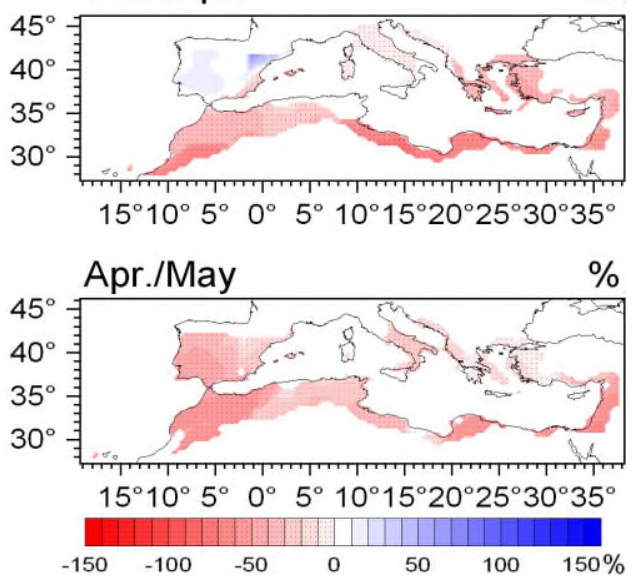

Figure 8. (a): Changes of Mediterranean Precipitation according to statistical downscaling assessments using ECHAM4/OPYC3 predictors $(1000 \mathrm{hPa}-/ 500 \mathrm{hPa}$-geopotential heights and $1000 \mathrm{hPa}$-specific humidity). Differences of the mean 2-month precipitation between the periods 2071-2100 and 1990-2019 in mm (left side) and percentages in relation to the mean of the period 1990-2019 (right side). Statistical downscaling technique: CCA. Scenario: SRESB2. (b): Signal/noise ratio of the differences. Transverse hatching: signal/noise ratio greater 1 (confidence level $=68.3 \%$ ); Cross hatching: signal/noise ratio $>1.960$ (confidence level $=95 \%$ ). This figure is available in colour online at www.interscience.wiley.com/ijoc 


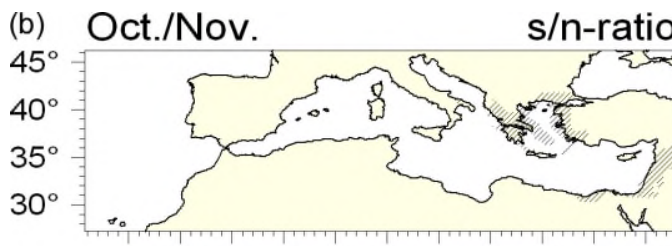

$15^{\circ} 10^{\circ} 5^{\circ} 0^{\circ} 5^{\circ} 10^{\circ} 15^{\circ} 20^{\circ} 25^{\circ} 30^{\circ} 35^{\circ}$

Dec./Jan.

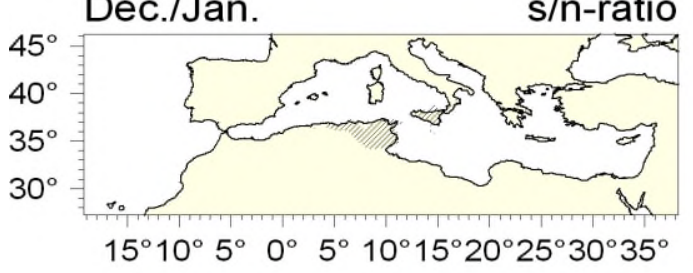

Feb./Mar

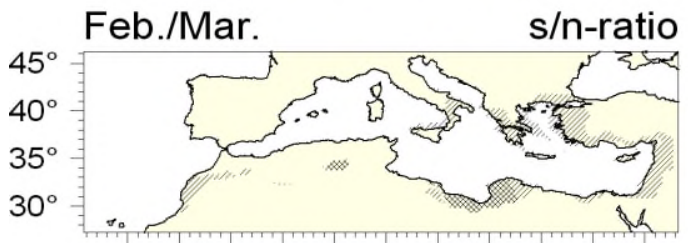

$15^{\circ} 10^{\circ} 5^{\circ} 0^{\circ} 5^{\circ} 10^{\circ} 15^{\circ} 20^{\circ} 25^{\circ} 30^{\circ} 35^{\circ}$

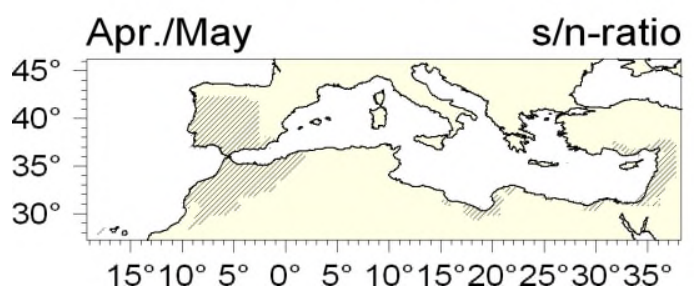

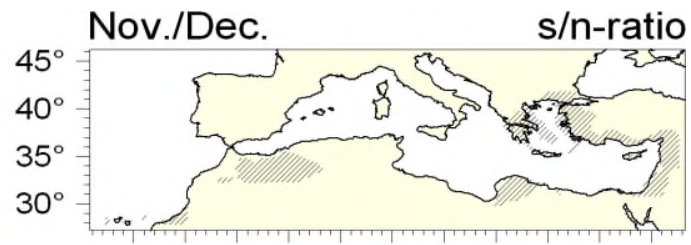

$15^{\circ} 10^{\circ} 5^{\circ} 0^{\circ} 5^{\circ} 10^{\circ} 15^{\circ} 20^{\circ} 25^{\circ} 30^{\circ} 35^{\circ}$

Jan./Feb. s/n-ratio
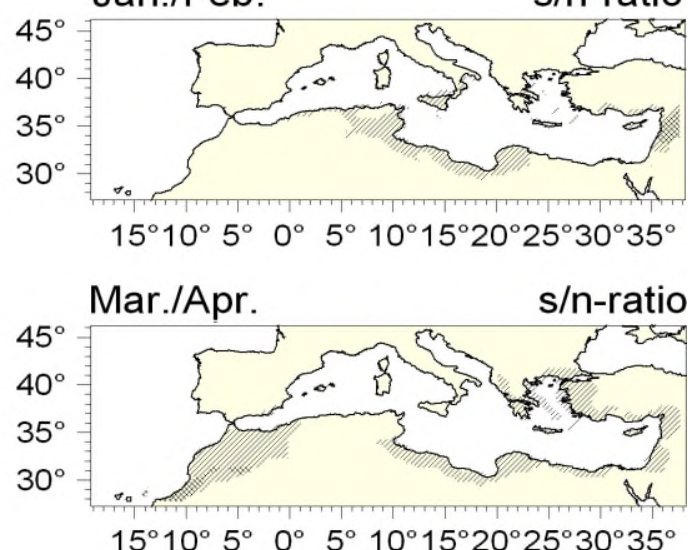

$15^{\circ} 10^{\circ} 5^{\circ} 0^{\circ} 5^{\circ} 10^{\circ} 15^{\circ} 20^{\circ} 25^{\circ} 30^{\circ} 35^{\circ}$

Figure 8. (Continued).

including northwestern Morocco and the Ligurian coast for all assessments based on SRES B2 assumptions.

The focus, however, is on the long-term variations and changes, and these are mainly quite similar between different assessments. Thus, only one example is presented in detail: Figure 8 shows the assessment results for all 2-month periods from October to May derived from the ECHAM4 scenario B2 run. The figure includes the 2-month mean rainfall differences between the 30-year periods 2071-2100 and 1990-2019 as well as the corresponding percentage changes. Additionally, maps of precipitation changes for November/December-February/March resulting from downscaling the output from three ECHO-G ensemble members are shown in Figure 9. The varying initial conditions of these ensemble members (Wagner, 2004) do not imply substantial differences in the future rainfall assessments. There are only some small distinctions, like the more pronounced increases of November/December precipitation in the central-northern Mediterranean area based on ECHO-G(1) predictors compared to predictors from the other ECHO-G ensemble members. Thus, the general rainfall changes summarized below do not result from the predictor output of a particular model run, but are reproduced as well with output from different ensemble members. The same is true for using predictor output from a different climate model: Figure 10 shows the precipitation changes for November/December-February/March downscaled from the output of the HadCM3 run. Predictors from this SRES B2 model run lead to similar results in the statistical downscaling models as for predictors from the corresponding ECHAM4 run (Figure 8).

The main results may be summarized as follows: At the beginning of the rainy season in October/November, most of the Mediterranean area is characterized by precipitation decreases. The generally drier conditions agree with similar changes obtained by Palutikof et al. $(1994,2002)$ for some Mediterranean areas in the autumn season. Results from the STARDEX project indicate decreases in mean rainfall and most indices of extremes for autumn in western Iberia and Greece. A remarkable exception is the east coast of Spain exhibiting October/November increases in all the different assessment versions considered in this section. Note that Gao et al. (2006) report positive precipitation changes in autumn south of the Alps, east of the Pyrenees and Jura Mountains, and over the eastern Hellenic Peninsula due to a more pronounced easterly and southeasterly circulation.

In November/December precipitation increases are shifted to the central-northern parts of the Mediterranean area. Next, in December/January, substantial increases are estimated for the whole western Mediterranean region, extending further east to most of Italy, 
(a) ECHO-G(1)

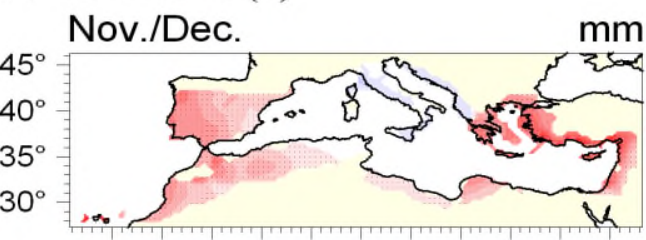

$15^{\circ} 10^{\circ} 5^{\circ} 0^{\circ} 5^{\circ} 10^{\circ} 15^{\circ} 20^{\circ} 25^{\circ} 30^{\circ} 35^{\circ}$

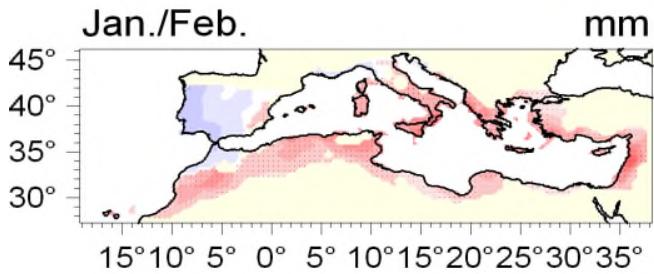

(b) ECHO-G(2)

Nov./Dec.

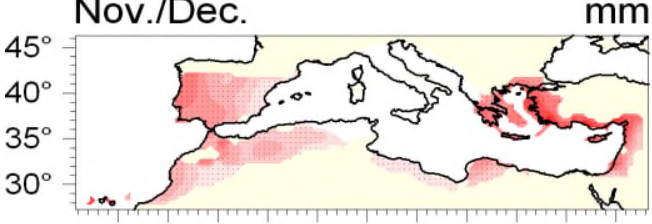

$15^{\circ} 10^{\circ} 5^{\circ} 0^{\circ} 5^{\circ} 10^{\circ} 15^{\circ} 20^{\circ} 25^{\circ} 30^{\circ} 35^{\circ}$

Jan./Feb.

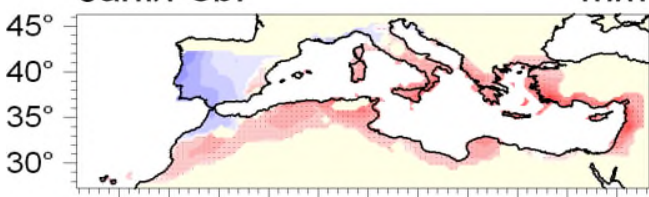

$15^{\circ} 10^{\circ} 5^{\circ} 0^{\circ} 5^{\circ} 10^{\circ} 15^{\circ} 20^{\circ} 25^{\circ} 30^{\circ} 35^{\circ}$

(c) ECHO-G(3)

Nov./Dec.

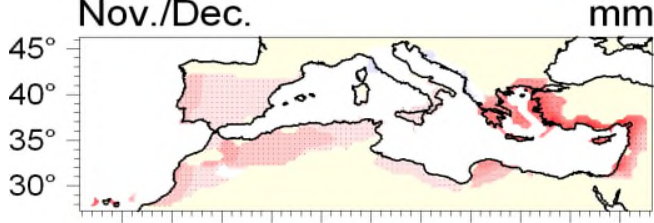

$15^{\circ} 10^{\circ} 5^{\circ} 0^{\circ} 5^{\circ} 10^{\circ} 15^{\circ} 20^{\circ} 25^{\circ} 30^{\circ} 35^{\circ}$

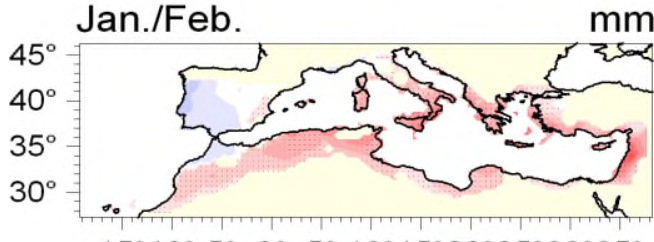

$15^{\circ} 10^{\circ} 5^{\circ} 0^{\circ} 5^{\circ} 10^{\circ} 15^{\circ} 20^{\circ} 25^{\circ} 30^{\circ} 35^{\circ}$

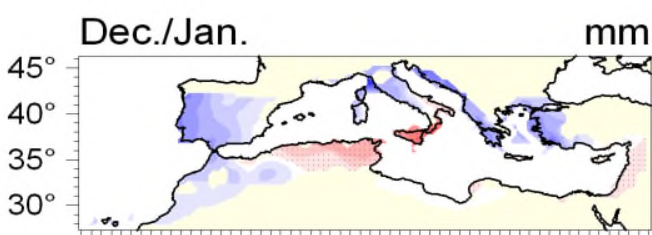

$15^{\circ} 10^{\circ} 5^{\circ} 0^{\circ} 5^{\circ} 10^{\circ} 15^{\circ} 20^{\circ} 25^{\circ} 30^{\circ} 35^{\circ}$
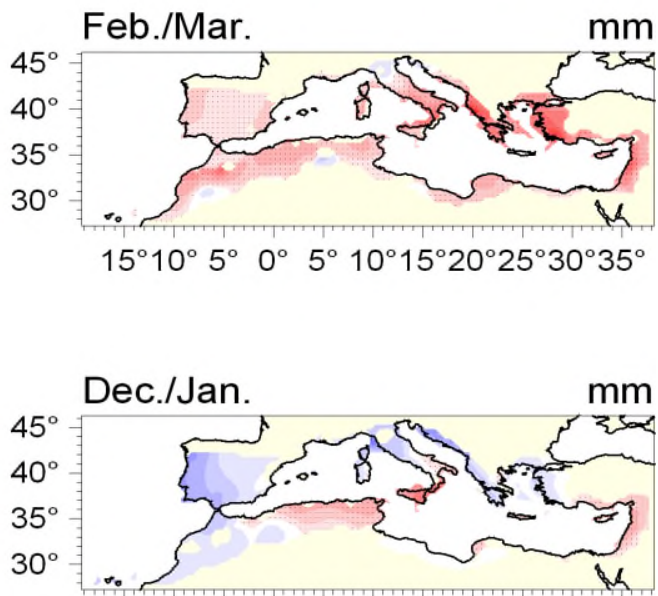

$15^{\circ} 10^{\circ} 5^{\circ} 0^{\circ} 5^{\circ} 10^{\circ} 15^{\circ} 20^{\circ} 25^{\circ} 30^{\circ} 35^{\circ}$

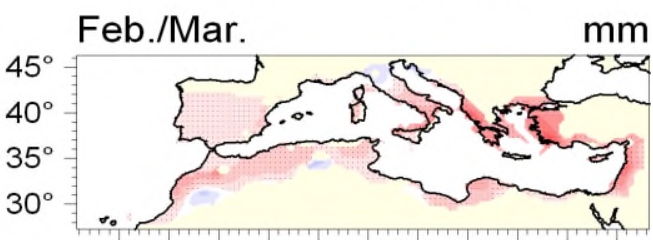

$15^{\circ} 10^{\circ} 5^{\circ} 0^{\circ} 5^{\circ} 10^{\circ} 15^{\circ} 20^{\circ} 25^{\circ} 30^{\circ} 35^{\circ}$

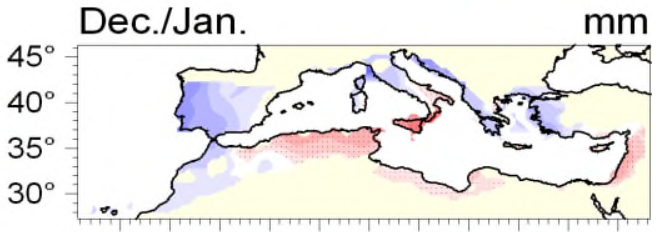

$15^{\circ} 10^{\circ} 5^{\circ} 0^{\circ} 5^{\circ} 10^{\circ} 15^{\circ} 20^{\circ} 25^{\circ} 30^{\circ} 35^{\circ}$

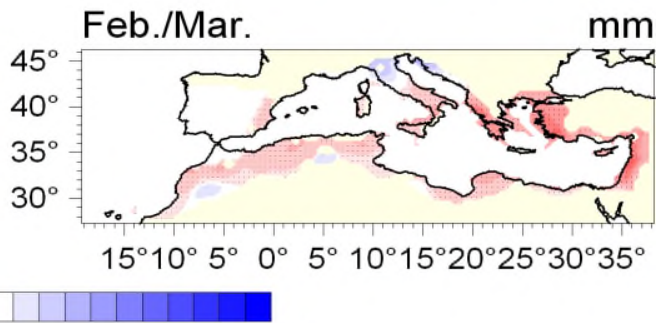

$-100-80-60-40-20 \quad 0 \quad 20 \quad 40 \quad 60 \quad 80100 \mathrm{~mm}$

Figure 9. Changes of Mediterranean Precipitation according to statistical downscaling assessments using predictors (1000 hPa-/500 hPageopotential heights and $1000 \mathrm{hPa}$-specific humidity) from three ECHO-G ensemble members. Differences of the mean 2-month precipitation between the periods 2071-2100 and 1990-2019 in mm. Statistical downscaling technique: CCA. Scenario: SRESB2. This figure is available in colour online at www.interscience.wiley.com/ijoc

Dalmatia and up to the Aegean region. The changing pattern which arises from the use of predictors from the ECHO-G A2 scenario run, shows pronounced increases in the above-mentioned regions by November/December, continuing, with varying spatial extent, until February/ March (not shown). Increasing wintertime precipitation for the Iberian Peninsula and parts of Italy under increased greenhouse warming conditions is reported in 

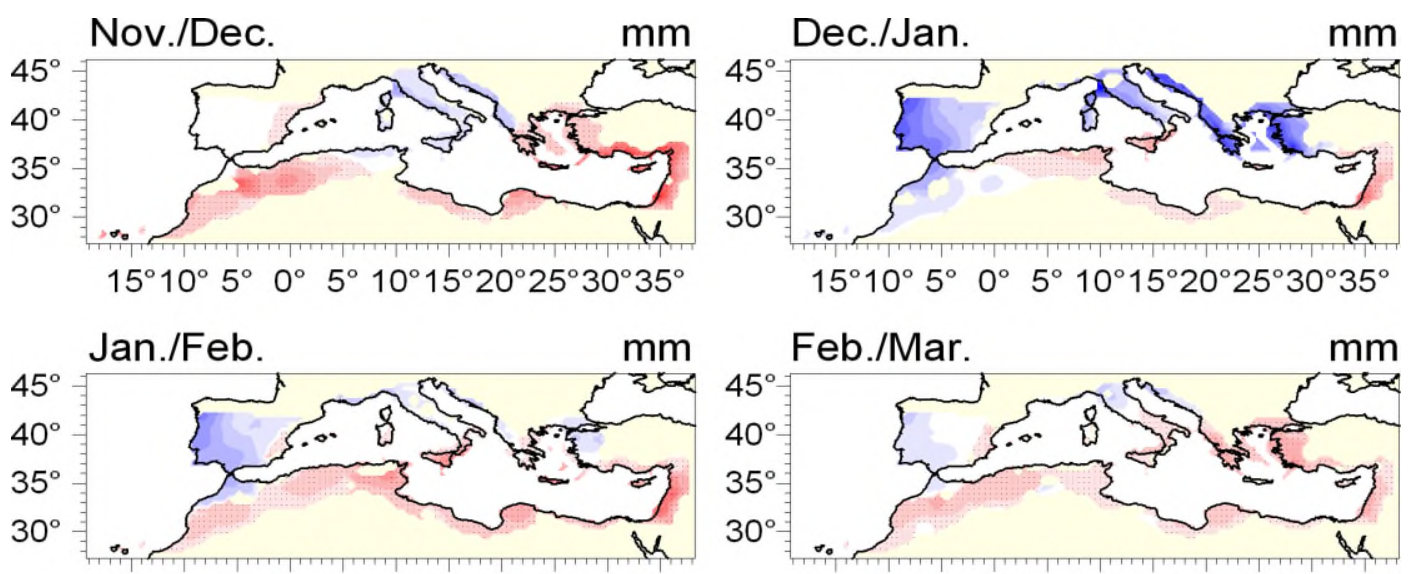

$15^{\circ} 10^{\circ} 5^{\circ} 0^{\circ} 5^{\circ} 10^{\circ} 15^{\circ} 20^{\circ} 25^{\circ} 30^{\circ} 35^{\circ}$

$15^{\circ} 10^{\circ} 5^{\circ} 0^{\circ} 5^{\circ} 10^{\circ} 15^{\circ} 20^{\circ} 25^{\circ} 30^{\circ} 35^{\circ}$

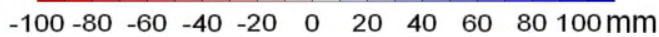

Figure 10. Changes of Mediterranean Precipitation according to statistical downscaling assessments using HadCM3 predictors (Mean Sea Level Pressure, geopotential heights of the $500 \mathrm{hPa}$-level and specific humidity in $2 \mathrm{~m}$ height). Differences of the mean 2 -month precipitation between the periods 2071-2100 and 1990-2019 in mm. Statistical downscaling technique: CCA. Scenario: SRESB2. This figure is available in colour online at www.interscience.wiley.com/ijoc

other modelling studies as well, for instance by Gibelin and Déqué (2003), Trigo and Palutikof (2001), Murphy (2000) and Palutikof and Wigley (1996). A pattern with rainfall increase in the northern and western parts and decrease in the southern and eastern parts during winter is also obtained from time-slice experiments by Cubasch et al. (1996). According to Figures 8-10 the eastern and southern Mediterranean areas are mainly characterized by rather weak decreases in rainfall, while only in Tunisia and Sicily do distinctly stronger decreases occur.

In January/February, all assessments point to substantial precipitation decreases in the eastern Mediterranean area. Such decreases are often estimated for this region, see for example Gibelin and Déqué (2003), Murphy (2000), Palutikof et al. (1994), and Jacobeit (1994a). A reduction is also found again in the southern and central parts of the Mediterranean area, particularly in Tunisia and Sicily. Precipitation decreases in winter for the Maghreb, strongest in the Moroccan region, are modelled by Räisänen et al. (2004). Gibelin and Déqué (2003) obtain similar results for the coastal areas of Tunisia and Algeria. In contrast to that, rainfall increases continue to appear in the western and northern Mediterranean regions during January/February (Figures 8-10). This is in general accordance to simulation results by Giorgi et al. (2004) showing rainfall increases for the DJF season approximately north of $42^{\circ}$ latitude. Gao et al. (2006) also assess DJF precipitation increases for most of France, the Alpine region and southeastern Europe due to increased Atlantic storm activity. Regarding precipitation extremes, a general tendency towards decreases is assessed by Frei et al. (2006) for the Mediterranean region in winter.

For the following months, the synopsis of the different model results indicates a less uniform pattern for the western and northern regions, with minor decreases in most cases. Only in April/May do all assessments show a consistent decline of precipitation amounts for the Iberian Peninsula. Fewer rain days during spring for southeast Spain are also indicated in the assessment by Goodess and Palutikof (1998). Along with the continuously negative changes in the other parts, the whole Mediterranean area is generally affected by drier conditions in spring. In contrast to that, results from regression analysis by Palutikof and Wigley (1996) indicate increased rainfall to the north of the Mediterranean Sea and decreased rainfall to the south during spring. Around this drier region, the northwestern parts of northern Africa stand out as a region of the most pronounced decreases in precipitation (see Figure 8, also reported by Jacobeit, 1994b).

\section{Conclusions}

The IPCC third assessment report (Houghton et al., 2001) has recommended further statistical downscaling studies with careful attention to the choice of predictors (p. 622) and an application of different techniques to a range of AOGCM simulations (p. 586). Both have been performed in the present study, and another step forward may be seen in the extended consideration of uncertainties including non-stationarities of the downscaling relationships and their degree of capturing the response to greenhouse gas forcing. In particular, Mediterranean precipitation changes for the 21 st century were assessed by means of statistical downscaling techniques using the simulated model output of several large-scale predictor fields (geopotential heights of various tropospheric levels, specific and relative humidity, and SSTs of the North Atlantic Ocean and the Mediterranean Sea). CCA as well as multiple regression analyses were used to establish predictor-predictand-relationships in ten different calibration periods each leaving out a different 5-year 
period from the whole study period 1948-1998. These remaining periods were used to verify the performance of the statistical models, respectively. This procedure led to ensembles of statistical models for the assessment of future Mediterranean precipitation changes. An advantage of this ensemble method is that non-stationarities in the circulation-rainfall relationships are particularly taken into account, but this is restricted by the fact that the 50-year training dataset is not long enough to sample all independent episodes of low-frequency variability. But in conjunction with the performance of a 'perfect model' study and through the use of large-scale predictor output from different AOGCM runs including several numerical ensemble members with different initial conditions, a number of important uncertainties in future predictions could be addressed without claiming to have captured them all. In any case, these are only one part within the overall cascade of uncertainty in climate prediction extending from future emissions to a changed forcing, to particular GCM responses, and to the transference down to regional scales. Just the latter has been focussed on in this paper.

Given the wide range of statistical downscaling models actually derived, their different quality within the verification periods was used to select the best predictor combination and the more suitable statistical technique for the assessment of Mediterranean precipitation changes. The best performance was achieved with the predictor combination $1000 \mathrm{hPa} / 500 \mathrm{hPa}$ geopotential heights and specific humidity. Even though the additional inclusion of specific humidity results only in a small improvement of model quality compared to models using geopotential heights alone, it may result in substantially modified changes of future precipitation amounts. In contrast to that, SSTs only sporadically exhibit a noticeable self-contained influence on Mediterranean precipitation variability. Altogether, it is evident that circulation-type predictors are of primary importance, but there is still a need to explore further the suitability of other large-scale predictors within the framework of statistical downscaling studies. When using different types of predictors (e.g. circulation and climate-related), CCA seems to be an appropriate technique, particularly since it provides a consistent whole-area analysis without varying subregional effects.

Using $1000 \mathrm{hPa} / 500 \mathrm{hPa}$ geopotential heights and specific humidity as predictors and assuming SRES B2 scenario conditions, a shortening and at the same time an increase in rainfall amount of the wet season arises for the western and northern Mediterranean regions: the statistical downscaling models predict precipitation increases in winter for the period 2071-2100 compared to $1990-2019$, whereas precipitation decreases dominate in autumn and spring. The eastern and southern parts of the Mediterranean area, on the other hand, exhibit mainly negative precipitation changes throughout the period from October to May, under enhanced greenhouse warming conditions.
Circulation dynamics point to enhanced anti-cyclonic conditions over the study area as a reason for precipitation decreases in the transitional seasons. In contrast to that, cyclonic conditions in the western and northern parts of the Mediterranean area show an increased dominance in winter, particularly in December and January. This could be an effect of stronger cyclonic activity in the western Mediterranean area, especially around the Gulf of Genova, associated with a more southerly path of storm tracks linked with a pressure rise centred over central Europe in these months as simulated by some AOGCMs (see Hertig, 2004). In this context, enhanced atmospheric humidity can be regarded as an additional factor for higher rainfall amounts.

Otherwise, broad precipitation decreases result for many parts of the Mediterranean area. These reductions could have serious impacts on water supply, exacerbated by the anticipated temperature rise and its associated evaporation enhancement (Palutikof et al., 1994). But also the possible intensification and shortening of the Mediterranean rainy season in the western and northern parts would form a major challenge in the context of water management for agriculture, tourism and landscape ecology

\section{Acknowledgements}

The authors would like to thank Sebastian Wagner and Eduardo Zorita of the Institute for Coastal Research at the GKSS and the DKRZ for the provision of the ECHO$\mathrm{G}$ and ECHAM4/OPYC3 data. Financial support was provided by the DFG (German Research Foundation) under contract JA 831/3-1. The authors were further supported by the European Commission under contract EVK2-CT-2002-00161 EMULATE.

\section{References}

Barnett T, Preisendorfer R. 1987. Origins and levels of monthly and seasonal forecast skill for the United States surface air temperatures determined by canonical correlation analysis. Monthly Weather Review 115: 1825-1850.

Beckmann BR, Buishand TA. 2002. Statistical downscaling relationships for precipitation in the Netherlands and North Germany. International Journal of Climatology 22: 15-32.

Bigg GR, Jickells TD, Liss PS, Osborn TJ. 2003. The role of the oceans in climate. International Journal of Climatology 23: 1127-1159.

Buishand TA, Brandsma T. 1999. Dependance of precipitation on temperature at Florence and Livorno (Italy). Climate Research 12: $53-63$.

Charles SP, Bates BC, Whetton PH, Hughes JP. 1999. Validation of downscaling models for changed climate conditions: case study of southwestern Australia. Climate Research 12: 1-14.

Conway D, Wilby RL, Jones PD. 1996. Precipitation and air flow indices over the British Isles. Climate Research 7: 169-183.

Corte-Real J, Zhang X, Wang X. 1995. Downscaling GCM information to regional scales: a non-parametric multivariate regression approach. Climate Dynamics 11: 413-424.

Covey C, AchutaRao KM, Lambert SJ, Taylor KE. 2000. Intercomparison of Present and Future Climates Simulated by Coupled OceanAtmosphere GCMs. Program for Climate Model Diagnosis and Intercomparison, Lawrence Livermore National Laboratory, University of California: Livermore, CA, PCMDI Report No 66.

Cubasch U, von Storch H, Waszkewitz J, Zorita E. 1996. Estimates of climate change in southern Europe derived from dynamical climate model output. Climate Research 7: 129-149. 
Déqué M, Marquet P, Jones RG. 1998. Simulation of climate change over Europe using a global variable resolution general circulation model. Climate Dynamics 14: 173-189.

Dünkeloh A, Jacobeit J. 2003. Circulation dynamics of Mediterranean precipitation variability 1948-1998. International Journal of Climatology 23: 1843-1866.

Easterling DR. 1999. Development of regional climate scenarios using a downscaling approach. Climatic Change 41: 635-640.

Frei C, Schöll R, Fukutome S, Schmidli J, Vidale PL. 2006. Future change of precipitation extremes in Europe: Intercomparison of scenarios from regional climate models. Journal of Geophysical Research 111: D06105.

Gao X, Pal JS, Giorgi F. 2006. Projected changes in mean and extreme precipitation over the Mediterranean region from a high resolution double nested RCM simulation. Geophysical Research Letters 33: L03706.

Gibelin A-L, Déqué M. 2003. Anthropogenic climate change over the Mediterranean region simulated by a global variable resolution model. Climate Dynamics 20: 327-339.

Giorgi F, Mearns LO. 1999. Introduction to special section: Regional climate modeling revisited. Journal of Geophysical Research 104: 6335-6352.

Giorgi F, Bi X, Pal J. 2004. Mean, interannual variability and trends in a regional climate change experiment over Europe. II: Climate change scenarios (2071-2100). Climate Dynamics 23: 839-858.

Goodess CM, Palutikof JP. 1998. Development of daily rainfall scenarios for southeast Spain using a circulation-type approach to downscaling. International Journal of Climatology 10: 1051-1083.

Gordon C, Cooper C, Senior CA, Banks H, Gregory JM, Johns TC, Mitchell JFB, Wood RA. 2000. The simulation of SST, sea ice extents and ocean heat transports in a version of the Hadley Centre coupled model without flux adjustments. Climate Dynamics 16: $147-168$.

Gyalistras D, von Storch H, Fischlin A, Beniston M. 1994. Linking GCM-simulated climatic changes to ecosystem models: case studies of statistical downscaling in the Alps. Climate Research 4: 167-189.

Hertig E. 2004. Niederschlags- und Temperaturabschätzungen für den Mittelmeerraum unter anthropogen verstärktem Treibhauseffekt. $\mathrm{PhD}$ thesis published online at http://opus.bibliothek.uniwuerzburg.de/opus/volltexte/2004/874/.

Hewitson BC, Crane RG. 2006. Consensus between GCM climate change projections with empirical downscaling: precipitation downscaling over South Africa. International Journal of Climatology 26: $1315-1337$

Hibler W. 1979. A dynamic-thermodynamic sea-ice model. Journal of Physical Oceanography 9: 815-846.

Houghton JT, Callander BA, Varney SK (eds). 1992. Climate Change 1992- The Supplementary Report to the IPCC Scientific Assessment. Cambridge University Press: Cambridge; 205.

Houghton JT, Ding Y, Griggs DJ, Noguer M, van der Linden PJ, Xiaosu D (eds). 2001. Climate Change 2001: The Scientific Basis. Contribution of the Working Group I to the Third Assessment Report of the Intergovernmental Panel on Climate Change (IPCC). Cambridge University Press: Cambridge; 944.

Jacobeit J. 1993. Regionale Unterschiede im atmosphärischen Zirkulationsgeschehen bei globalen Klimaveränderungen. Die Erde 124: $63-77$.

Jacobeit J. 1994a. Empirische Abschätzungen zur Änderung des Winterniederschlags im Mittelmeerraum bei anthropogen verstärktem Treibhauseffekt. PIK-Reports 1: 117-121.

Jacobeit J. 1994b. Empirical estimations of Mediterranean rainfall changes in the transitional seasons due to enhanced greenhouse warming. In Contemporary Climatology, Brazdil R, Kolnar M (eds). Commission on Climatology of the IGU: Brno; 266-271.

Jacobeit J. 1996. Atmospheric circulation changes due to increased greenhouse warming and its impact on seasonal rainfall in the Mediterranean area. In Proceedings of the Regional Workshop an Climate Variability and Climate Change Vulnerability and Adaption, Praha, 71-80

Jacobeit J. 2000. Rezente Klimaentwicklung im Mittelmeerraum. Petermanns Geographische Mitteilungen 144: 26-37.

Jacobeit J, Dünkeloh A, Hertig E. 2007. Mediterranean rainfall changes and their causes. In Global Change: Enough Water for All? Lozan JL, Graßl H, Hupfer P, Menzel L, Schönwiese CD (eds). Wissenschaftliche Auswertungen: Hamburg; 195-199.

Kalnay E, Kanamitsu M, Kistler R, Collins W, Deaven D, Gandin L, Iredell M, Saha S, White G, Woollen J, Zhu Y, Chelliah M, Ebisuzaki W, Higgins W, Janowiak J, Mo KC, Ropelewski C,
Wang J, Leetmaa A, Reynolds R, Jenne R, Joseph D. 1996. The NCEP/NCAR 40-Year reanalysis project. Bulletin of the American Meteorological Society 77: 437-471.

Kistler R, Kalnay E, Collins W, Saha S, White G, Woollen J, Chelliah M, Ebisuzaki W, Kanamitsu M, Kousky V, van den Dool H, Jenne R, Fiorino M. 2001. The NCEP/NCAR 50-Year Reanalysis: Monthly means CD-ROM and documentation. Bulletin of the American Meteorological Society 82: 247-268.

Legutke S, Voss R. 1999. The Hamburg atmosphere-ocean coupled model ECHO-G. Technical Report 18, German Climate Computer Center (DKRZ).

Lionello P, Malanotte-Rizzoli P, Boscolo R, Alpert P, Artale V, Li L, Luterbacher J, May W, Trigo R, Tsimplis M, Ulbrich U, Xoplaki E. 2006a. The Mediterranean climate: An overview of the Main Characteristics and Issues. In Mediterranean Climate Variability, Lionello P, Malanotte-Rizzoli P, Boscolo R (eds). Elsevier: Amsterdam; 1-18.

Lionello P, Bhend J, Buzzi A, Della-Marta PM, Krichak SO, Jansa A, Maheras P, Sanna A, Trigo IF, Trigo R. 2006b. Cyclones in the Mediterranean region: Climatology and effects on the environment. In Mediterranean Climate Variability, Lionello P, MalanotteRizzoli P, Boscolo R (eds). Elsevier: Amsterdam; 325-365.

Min S-K, Legutke S, Hense A, Kwon WT. 2005. Internal variability in a 1000-year control simulation with the coupled climate model ECHO-G-I. Near-surface temperature, precipitation and mean sea level pressure. Tellus 57A: 605-621.

Mitchell TD, Jones PD. 2005. An improved method of constructing a database of monthly climate observations and associated high-resolution grids. International Journal of Climatology 25: 693-712.

Mitchell TD, Carter TR, Jones PD, Hulme M, New M. 2004. A comprehensive set of high-resolution grids of monthly climate for Europe and the globe: the observed record (1901-2000) and 16 scenarios (2001-2100). Tyndall Centre for Climate Change Research. Working Paper 55, 30.

Murphy J. 2000. Predictions of climate change over Europe using statistical and dynamical downscaling techniques. International Journal of Climatology 20: 489-501.

Nakicenovic N, Swart R (eds). 2000. Emissions Scenarios 2000 Special Report of the Intergovernmental Panel on Climate Change. Cambridge University Press: Cambridge; 570.

New M, Hulme M, Jones P. 1999. Representing twentieth century space-time climate variability. I: Development of a 1961-1990 mean monthly terrestrial climatology. Journal of Climate 12: 829-856.

New M, Hulme M, Jones P. 2000. Representing twentieth century space-time climate variability. II: Development of 1901-1996 monthly grids of terrestrial surface climate. Journal of Climate 13: 2217-2238.

Oberhuber JM. 1993. The OPYC Ocean General Circulation Model. Deutsches Klimarechenzentrum: Hamburg; 130, DKRZ Report No. 7.

Oesterle H, Gerstengarbe FW, Werner PC. 2003. Homogenisierung und Aktualisierung des Klimadatensatzes der Climate Research Unit der Universitaet of East Anglia, Norwich. Terra Nostra 2003/6. Alfred- Wegener- Stiftung: Berlin; 326-329.

Palmer TN. 1999. A nonlinear dynamical perspective on climate prediction. Journal of Climate 12: 575-592.

Palutikof JP, Wigley TML. 1996. Developing climate change scenarios for the Mediterranean region. In Climatic Change and the Mediterranean, Vol. 2, Jeftic L, Keckes S, Pernetta JC (eds) Arnold: London; 27-56.

Palutikof JP, Goodess CM, Guo X. 1994. Climate change, potential evapotranspiration and moisture availability in the Mediterranean Basin. International Journal of Climatology 14: 853-869.

Palutikof JP, Goodess CM, Watkins SJ, Holt T. 2002. Generating rainfall and temperature scenarios at multiple sites: Examples from the Mediterranean. Journal of Climate 15: 3529-3548.

Pope VD, Gallani ML, Rowntree PR, Stratton RA. 2000. The impact of new physical parametrizations in the Hadley centre climate model: HadAM3. Climate Dynamics 16: 123-146.

Preisendorfer RW. 1988. Principal Component Analysis in Meteorology and Oceanography. Developments in Atmospheric Science 17. Elsevier: Amsterdam.

Räisänen J, Hansson U, Ullerstig A, Döscher R, Graham LP, Jones C, Meier HEM, Samuelsson P, Willén U. 2004. European climate in the late twenty- first century: regional simulations with two driving global models and two forcing scenarios. Climate Dynamics 22: $13-31$ 
Rao CR. 1973. Linear Statistical Inference and its Applications. Wiley Series in Probability and Mathematical Statistics. Wiley: New York; 625.

Rapp J, Schönwiese CD. 1995. Atlas der Niederschlags- und Temperaturtrends in Deutschland 1891-1990.- Frankfurter Geowissenschaftliche Arbeiten, Serie B, Band 5, 255.

Rayner NA, Horton EB, Parker DE, Folland CK, Hackett RB. 1996 Version 2.2 of the Global Sea- Ice and Sea Surface Temperature data set, 1903-1994. Climate Research Technical Note 74, available through the Hadley Centre for Climate Prediction and Research, Meteorological Office, Bracknell, UK, 21

Richman MB. 1986. Rotation of principal components. Journal of Climatology 6: 293-335.

Roeckner E, Arpe K, Bengtsson L, Christoph M, Claussen M, Dümenil L, Esch M, Giorgetta M, Schlese U, Schulzweida U. 1996. The atmospheric General Circulation model ECHAM-4: Model description and simulation of the present-day climate. Max-PlanckInstitute for Meteorology Report No. 218, 90.

Smith TM, Livezey RE, Stokes DC. 1996. Reconstruction of historica sea surface temperatures using empirical orthogonal functions. Journal of Climate 9: 1403-1420.

Timbal B, Mahfouf JF, Royer JF, Cariolle D. 1995. Sensitivity to prescibed changes in sea surface temperature and sea ice in doubled carbon dioxide experiments. Climate Dynamics 12: 1-20.

Tompkins AM, Emanuel KA. 2000. The vertical resolution sensitivity of simulated equilibrium temperature and water vapour profiles. Quartarly Journal of the Royal Meteorological Society 126: 1219-1238.

Trigo RM, Palutikof JP. 2001. Precipitation scenarios over Iberia: A comparison between direct GCM output and different downscaling techniques. Journal of Climate 14: 4422-4446.

von Storch H. 1999. The global and regional climate system. In Anthropogenic Climate Change. von Storch H, Floeser G (eds) Springer: Heidelberg; 3-36.

von Storch H, Zwiers FW. 1999. Statistical Analysis in Climate Research. Cambridge University Press: Cambridge; 484. von Storch H, Zorita E, Cubasch U. 1993. Downscaling of global climate change estimates to regional scales: An application to Iberian rainfall in wintertime. Journal of Climate 6: 1161-1171.

Wagner S. 2004. The role of different forcings on the historical climate variability, with special consideration of the Dalton Minimum (1790-1830): a model study. PhD thesis, University of Hamburg, Department of Earth Sciences, external GKSS report 2004/13.

Wanner H, Rickli R, Salvisberg E, Schmutz C, Schüepp M. 1997. Global climate change and variability and its influence on alpine climate- concepts and observations. Theoritical and Applied Climatology 58: 221-243.

Weischet W. 2002. Einfuehrung in die Allgemeine Klimatologie. Gebrueder Borntraeger: Stuttgart; 276.

Wilby RL, Wigley TML. 1997. Downscaling general circulation model output: a review of methods and limitations. Progress in Physical Geography 21(4): 530-548.

Wilby RL, Wigley TML. 2000. Precipitation predictors for downscaling: observed and general circulation model relationships. International Journal of Climatology 20: 641-661.

Wolff J, Maier-Reimer E, Legutke S. 1997. The Hamburg Primitive Equation Model HOPE. Technical Report 18. German Climate Computer Center (DKRZ).

Xoplaki E, González-Rouco JF, Gyalistras D, Luterbacher J, Rickli R, Wanner H. 2003. Interannual summer air temperature variability over Greece and its connection to the large-scale atmospheric circulation and Mediterranean SSTs 1950-1999. Climate Dynamics 20: $537-554$

Zorita E, Kharin V, von Storch H. 1992. Atmospheric circulation and sea surface temperature in the North Atlantic area in winter: their interaction and relevance for Iberian precipitation. Journal of Climate 5: 1097-1108. North Atlantic.

Zorita E, Frias D, Fernandez J. 2006. Testing downscaling methods in the virtual reality of simulated climate. Abstracts of the 7. German Climate Meeting in Munich, 25-27. 